\title{
Protein corona and nanoparticles: how can we investigate on?
}

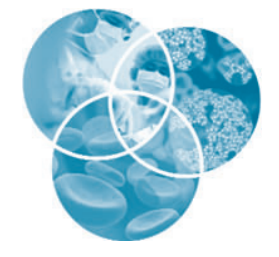

\section{Francesca Pederzoli, Giovanni Tosi, * Maria Angela Vandelli, Daniela Belletti,} Flavio Forni and Barbara Ruozi

\begin{abstract}
Nanoparticles (NPs) represent one of the most promising tools for drug-targeting and drug-delivery. However, a deeper understanding of the complex dynamics that happen after their in vivo administration is required. Particularly, plasma proteins tend to associate to NPs, forming a new surface named the 'protein corona' (PC). This surface is the most exposed as the 'visible side' of NPs and therefore, can have a strong impact on NP biodistribution, targeting efficacy and also toxicity. The PC consists of two poorly delimited layers, known as 'hard corona' (HC) and 'soft corona' (SC), that are affected by the complexity of the environment and the formed protein-surface equilibrium during in vivo blood circulation. The HC corona is formed by proteins strongly associated to the NPs, while the SC is an outer layer consisting of loosely bound proteins. Several studies attempted to investigate the $\mathrm{HC}$, which is easier to be isolated, but yielded poor reproducibility, due to varying experimental conditions. As a consequence, full mapping of the HC for different NPs is still lacking. Moreover, the current knowledge on the SC, which may play a major role in the 'first' interaction of NPs once in vivo, is very limited, mainly due to the difficulties in preserving it after purification. Therefore, multi-disciplinary approaches leading to the obtainment of a major number of information about the PC and its properties is strongly needed to fully understand its impact and to better support a more safety and conscious application of nanotechnology in medicine. @ 2017 Wiley Periodicals, Inc.
\end{abstract}

How to cite this article:

WIREs Nanomed Nanobiotechnol 2017, e1467. doi: 10.1002/wnan.1467

\section{INTRODUCTION}

Tn the last two decades, pharmaceutical research I programs have developed a progressively growing interest in nanomedicines for diagnostics, therapeutics and specific drug-delivery ${ }^{1}$ as confirmed by an increasing number of nanomedicines fully on market. In order to speed up the translatability of nanomedicines, understanding their fate in vivo is pivotal.

In vivo, nanomedicines are immediately covered by proteins from the bloodstream leading to the formation of what is called the 'protein corona' (PC). ${ }^{2,3}$ When the PC forms on NPs, it could govern the fate and

*Correspondence to: gtosi@unimore.it

Department of Life Sciences, University of Modena and Reggio Emilia, Modena, Italy

Conflict of interest: The authors have declared no conflicts of interest for this article. successes/failures of nanomedicines in terms of efficacy, targeting, toxicity, cellular interaction, cellular uptake, and biodistribution. ${ }^{4-8}$ Protein composition, architecture and structure are normally characterized by wellknown protocols that have been applied to the PC. The evidence is that to-date PC (or better 'protein corona + nanomedicine') is poorly characterized in terms of chemico-physical and structural features. Therefore, in this review, we aim to comment on the most relevant possibilities in terms of experimental methodologies to more completely characterize these new entities, and to furnish useful data to better predict the fate and efficiency of these drug delivery systems in vivo.

\section{HARD AND SOFT CORONA}

The PC is frequently described as being composed by a 'hard' (HC) and a 'soft' (SC) portions, with the 
binding force of the proteins to nanomaterial often considered as the discriminating criterion. ${ }^{9-12}$ Thus, the HC is generally defined as 'the corona composed by tightly bound proteins that do not readily desorb from the nanomaterial', whereas the SC is indicated as 'the corona featured by loosely bound proteins'. ${ }^{13}$ In addition to these definitions, Sakulkhu et al. (2013) separated the total PC of their SPION into three parts: soft, hard and tightly bound, suggesting the possibility to further discriminate another level of binding force for protein surrounding the nanomaterial. ${ }^{14}$

However, the definition of $\mathrm{HC}$ and SC can also take into account more complex issues relating to thermodynamic and kinetic matters, the interaction with nanomaterial and the functional/ biological responses.

As reported, ${ }^{15}$ from a thermodynamic point of view, the HC adsorbs onto the surface of NPs in a thermodynamically favorable manner with a large net binding energy of adsorption $\left(\Delta G_{\text {ads }}\right)$. This binding energy determines the stability of the proteinnanomaterial complex, as a consequence, proteins that adsorb with a large $\Delta G_{\text {ads }}$ have a low probability of desorption and tend to stay associated with the nanomaterial. ${ }^{16}$ On the other hand, proteins that adsorb with a small $\Delta G_{\text {ads }}$, easily desorb and return to solution, as in the case of SC. Thus, it is possible to divide protein adsorption and desorption into 'fast' and 'slow' components. According to this idea, Cedervall et al. modeled total plasma protein adsorption using a bi-exponential function. ${ }^{17}$ The Cedervall's model implicitly divides protein adsorption and desorption into 'fast' and 'slow' components, with its own 'effective' $k_{\text {on }}$ and $k_{\text {off. }}$. Since the fast and slow components of adsorption and desorption presumably represent the hard and soft coronas, in some recent papers, ${ }^{10,13,18}$ the SC and HC, respectively, are alternatively indicated with the terms 'fast component' and 'slow component', referring to desorption processes. On the other hand, considering the adsorption process, the fast and slow terms must be inverted. Adsorption/ desorption times and kinetic curves are unique to each nanomaterial and depend on many parameters. In this experiment, protein desorption to $\mathrm{N}$-isopropylacrylamide/ $\mathrm{N}$-tertbutylacrylamide (NIPAM/BAM) copolymer nanoparticles, showed a mean lifetime of $10 \mathrm{~min}$ for the fast component (SC), and $8 \mathrm{~h}$ for the slow component (HC). However, it remains almost impossible to clearly establish global standard parameters belonging to fast and slow components or, in other words, to SC and HC.

In order to better define the $\mathrm{HC}$ and SC, another debatable aspect consists in the interaction with nanomaterial. The HC is frequently considered as the portion of the PC directly interacting with the nanomaterial and the $\mathrm{SC}$ as the external portion of the $\mathrm{PC}$, which is interacting with the inner $\mathrm{HC}$ via protein-protein interactions. In support of this vision, Simberg and colleagues identified specific protein domains as responsible for $\mathrm{HC}$ adsorption on their iron oxide NPs. In particular, the authors attributed 'domain 5' (D5) for the adsorption of high molecular weight kininogen onto iron oxide nanoparticles. ${ }^{19}$ The precise mechanisms involved during adsorption and their relative contributions strongly depend on the proteins which interact and on the physicochemical properties of the nanomaterial; thus, it is very difficult, and not always possible, to determinate the protein domain that interacts with the nanomaterial, especially if the NPs are incubated in a complex fluid such as plasma.

It is also necessary to consider that, the $\mathrm{HC}$ results from both protein/protein and protein/nanomaterial interactions and that the stability of the PC is strongly dependent on both the type and the binding force of proteins forming the $\mathrm{HC}$, and that this should be known to predict the in vivo behaviour. Recently, Lynch et al. demonstrated the importance of the $\mathrm{HC}$ on the physiological response to a nanomaterial. ${ }^{20}$ In their experiments, the HC remained adsorbed onto the nanomaterial during biophysical events such as endocytosis, and even after translocation to a new physiological environment. On the contrary, the SC rapidly dissociated during translocation and was quickly lost. Moreover, the $\mathrm{HC}$ reflects the journey of the nanomaterial in the body compartments. For example, a nanomaterial that enters the blood through the lung may display dramatic differences in $\mathrm{HC}$ compositions, and in the resulting physiological responses with respect to the same nanomaterial directly injected in the bloodstream. ${ }^{21}$ However, this biological/functional distinction between $\mathrm{HC}$ and SC is not supported by solid data concerning the $\mathrm{SC}$, but is only limited on speculations based on $\mathrm{HC}$ results.

Similarly, the dynamics involving the SC equilibrium after in vivo administration represent a critical point to define the circulation stability of nanomaterials.

Overall, a precise and specific distinction between the $\mathrm{HC}$ and SC is hard to be defined due to poor experimental evidences aiming to univocally individuate and unambiguously discriminate the criteria. Therefore, multiple characterizations must be utilized to discriminate between the $\mathrm{HC}$ and SC and more completely understand the role of the $\mathrm{PC}$ on the fate of nanomedicines (Table 1). 
TABLE 1 | Schematic Illustration of Hard Corona and Soft Corona Characteristics

\begin{tabular}{ll}
\hline Hard Corona & \\
\hline Tightly bound proteins & Loosely bound proteins \\
$\uparrow\left|\Delta G_{\text {abs }}\right|$ & $\downarrow\left|\Delta G_{\text {abs }}\right|$ \\
$\downarrow k_{\text {off }}$ & $\uparrow k_{\text {off }}$ \\
Directly interacting with nanomaterials & Protein-protein interaction (and with nanomaterial too?) \\
Stable on NP surface and able to influence the functional response & Fleeting on NP surface and irrelevant for the functional response
\end{tabular}

$\mathrm{NP}$, nanoparticle.

\section{ANALYTICAL METHODS FOR CORONA EVALUATION}

The study of the PC can be separated into different points of view: analysis of PC structure (i.e., thickness), protein quantification (quantitative or semi-quantitative approach), study of protein affinity and stoichiometry, evaluation of protein conformation, analysis of NP-protein interaction and identification of the PC composition (qualitative approach). Overall, on the basis of the analytical methods applied in a study, two different approaches of investigation could be identified: in situ or ex situ. ${ }^{15}$ In situ techniques measure the NPs-PC complex directly into the protein solution where NPs are dispersed. Following this approach, the excessive sample manipulation is avoided and the incubation context is preserved allowing a reliable measurement of how the PC evolves in real time. On the contrary, ex situ techniques measure the PC after isolation of the NPs-PC complex from the physiological enviroment. ${ }^{15}$ In this contest, different isolation methods could be applied, depending on the experimental requirements. The most common used methods are:

- Centrifugation. Based on the different densities of nanomaterials relative to free proteins, centrifugation is, to-date, the most widely used method for isolation of the PC around nanomedicines. ${ }^{22-25}$ Centrifugation is a simple and quick isolation method and an efficient way to retrieve enough proteins for their safe identification using mass spectrometry analysis, as the quality of identification is strictly dependent on the available amount of material.

- Size exclusion chromatography (SEC). In order to isolate the corona in a less perturbing manner, SEC was recently proposed as an alternative to centrifugation. This technique separates NP-PC complexes from unbound proteins through a column containing a porous stationary phase. Separation takes place since NP-PC complexes are larger than the stationary phase pores, do not penetrate into the pores, and elute before the unbound proteins, which on the contrary can enter the pores and require a longer time to pass through the column.

This isolation method is less disruptive than centrifugation and weakly bound proteins may still be retrieved after the separation. ${ }^{17,20,26}$

- Magnetic separation/magnetic flow field fractionation $(\mathrm{MgFFF})$. This particular technique is based on the elution of magnetic NPs by means of a chromatography-like method in which the separation is carried out in a single liquid phase. $\mathrm{MgFFF}$ is characterized by the use of an external magnetic field applied perpendicularly to the direction of sample flow through an empty and thin ribbon like channel. ${ }^{27}$ As demonstrated by Ashby et al., this method allows the screening of proteins with distinct exchange kinetics in the corona around NPs. In fact, $\mathrm{MgFFF}$ provides for a separation in nonequilibrium conditions able to cause continuous dissociation of the protein-NP complexes inside the column; that way, the dissociated proteins are constantly washed away from the complexes by the protein-free mobile phase. ${ }^{18}$

\section{Analysis of the PC Structure}

- Dynamic light scattering (DLS). DLS allows the determination of the hydrodynamic diameter of colloidal particles and conjugates. Therefore, DLS measurements are useful to determine changes in the diameter of NPs before and after incubation in a biological environment. ${ }^{22} \mathrm{Sev}$ eral studies employed the DLS technique aiming to evaluate the extent of PC formation, and to correlate an increase in NP diameter after exposure to serum or plasma to the formation of a 
PC around the particle. ${ }^{24,25,28}$ The main advantage of DLS is the possibility to be used both in situ and after isolation of the NP-PC complex. However, in order to give reliable results, DLS measurements require a monodisperse population of NP-PC complexes with homogeneous shapes as it could strongly affect the hydrodynamic diameters. Recently, a very elegant approach on NP-PC complex size determination was given by Schmidt and co-workers ${ }^{29}$; in this paper, the aggregation dynamics as well as the impact of different chemico-physical properties of NPs on the PC-NP complex size were analyzed.

- Differential centrifugal sedimentation (DCS). DCS is able to separate the components of a mixture on the basis of their density and size, as larger and denser objects require lower centrifugal forces to sediment. DCS allows the size distribution measurements of NP-PC complexes also in situ, but limits may also be present. In fact, this technique forces the samples to be repeatedly centrifuged followed by removal of the pellet and repeated with increased centrifugal force. Moreover, this technology may risk exposing the samples contaminations and poor recovery. This method was applied to determine differences in size between bare and coronacoated NP systems. ${ }^{24,25}$

- Transmission electron microscopy (TEM). TEM is used to obtain images of the NPs before and after incubation in a biological fluid with the scope of determining the thickness of PC around the NPs. However, this technique requires a sample preparation, which may affect the morphology of NP-PC complexes. $^{25}$ In addition, counterstaining is required, since the small size of the NPs and the thin protein layer may provide insufficient contrast. ${ }^{30}$

\section{Protein Quantification}

- Bicinchoninic acid (BCA) assay. This test combines the reduction of $\mathrm{Cu}^{2+}$ to $\mathrm{Cu}^{1+}$ by peptide bonds of the protein in alkaline solution with the selective colorimetric reaction of $\mathrm{BCA}-\mathrm{Cu}^{1+}$ able to form a purple complex featured by absorption at $\lambda 562 \mathrm{~nm} .{ }^{31}$ In the case of PC-NP complexes, the BCA assay is performed to determine the total amount of proteins adsorbed onto NPs after incubation in plasma. ${ }^{32-34}$ Advantages of this technique are represented by its compatibility with several reagents or buffers present in the samples and the limited amount of sample required for the analysis. However, the reaction is time and cost expensive as the unit cost is higher than for other colorimetric methods, such as the Bradford assay. ${ }^{31}$

- Bradford assay. This test detects proteins on the basis of their binding to Coomassie brilliant blue, forming a protein-dye complex with a change in the solution color from red to blue, due to a shift in the peak absorbance of the dye from $\lambda 465 \mathrm{~nm}$ to $\lambda 595 \mathrm{~nm} .{ }^{31}$ As well as BCA assay, Bradford assay is employed in the determination of the amount of adsorbed proteins onto NPs. ${ }^{35,36}$ This colorimetric method is highly sensitive, quick and requires minimal amounts of sample for the analysis. In addition, it represents one of the less expensive colorimetric methods for protein quantification.

- Thermogravimetric analysis (TGA). This technique is commonly used to measure the amount of weight variation occurring after a thermodecomposition reaction in organic or semiorganic materials. Thus, the overall mass of the proteins adsorbed onto inorganic NP-surface can be determined by the loss of weight after the decomposition reaction. ${ }^{37}$

\section{Binding Affinity/Stoichiometry and Protein Interaction}

- Fluorescence correlation spectroscopy (FCS). This technique provides information on both kinetic and thermodynamic properties of fluorescent molecules in solution, exploiting the temporal relaxation of the measured fluorescence fluctuations and the amplitudes of the fluctuations, respectively. ${ }^{38}$ Thus, FCS experiments allow us to measure binding curves by exposing NPs in nanomolar dilutions to a wide range of protein concentrations and, thereby, yield information on the tendency of the protein to adsorb. ${ }^{39}$

- Size exclusion chromatography (SEC). This technique allows determination of the affinity and lifetime of the NP-protein interaction. Ideally, the separation of proteins and other compounds by SEC is based on the size of the analytes in solution. Generally, the pore size and/or geometry restrict access of molecules based on their Stokes radius. The largest molecules/structures, which are excluded from the pores, elute first. Subsequent molecules elute in 
order of decreasing size. ${ }^{40}$ In the case of the PC, if proteins exchange slowly from the particle, they will elute rapidly with the particles, while if the exchange is fast, the protein will elute at the same time as without particles. ${ }^{20}$

- Isothermal titration calorimetry (ITC). This method can be applied to measure the stoichiometry, affinity and enthalpy of NP-protein interaction. In this technique, protein is added to a NP suspension in the sample cell, and the difference in heat needed to keep both the sample and reference cells at the same temperature is measured. If the concentrations of both NPs and added protein are known, this technique provides information on the number of bound protein molecules per particle, the apparent affinity and the enthalpy change. ${ }^{17}$

- Surface plasmon resonance (SPR). SPR provides information on the adsorption kinetics. In this technique, NPs are anchored on the gold surface of the sensor chip, and proteins are injected to flow over the NP-modified surface. SPR measures the change of oscillation of surface plasmon waves that are caused by the adsorption of molecules onto the metal surface. ${ }^{17,41,42}$

- Quartz crystal microbalance (QCM). This technology, based on the piezoelectric effect, measures the resonant frequency shift correlated to mass changes at the oscillating quartz surface. Either proteins or NPs are immobilized onto a gold surface located on a quartz crystal; the binding partner is injected into the flow-chamber, passed over the quartz surface and the frequency monitored in real-time. Real-time and quantitative NP-protein binding profiles are obtained, and the association and dissociation constants can be determined by fitting to the Langmuir adsorption isotherm. ${ }^{43}$

- Z-potential measurement. Zeta potential is another approach for the screening of NPprotein interactions. Adsorbed proteins change the zeta potentials and the isoelectric points (IEP) of the particles, and the amount of the adsorbed protein on particle surfaces could be correlated with the zeta potential. ${ }^{22}$

- Computer simulation. Beside the experimental techniques, computer or in silico simulation of $\mathrm{NP}$-protein interactions is another possible strategy to predict PC characterization and composition. In fact, simulation provides information on protein orientation and conformation with high spatial and temporal resolution and it is applied to study protein adsorption to
NPs as function of surface ligand structure, surface curvature and protein identity. ${ }^{15}$

\section{Protein Conformation}

- Circular dichroism (CD) spectroscopy. CD measures the spectra of different protein secondary structures, as they possess their own CD spectra in the UV region. ${ }^{44-46}$ This technique can provide information on protein structural changes resulting from the interaction with NPs, but requires relatively high concentration of the sample and cannot be applied to complex protein mixtures. ${ }^{41}$

- Fourier-transform infrared (FTIR) spectroscopy. Similar to CD spectroscopy, FTIR allows the determination of conformational changes of proteins. The protein secondary structures are estimated on the basis of the absorption of amide bonds. Among the amide I, II, and III bands, the amide I vibrational band $\left(1700-1600 \mathrm{~cm}^{-1}\right)$ is the most sensitive and frequently used to determine protein conformation. ${ }^{41}$ The FTIR method allows the detection of NP-PC complexes already at a very early stage as well as highlight conformational changes during the ongoing aggregation process.

- Raman spectroscopy (RS). As with FTIR, RS investigates the vibrational modes of molecules, giving complementary information. Raman spectra of proteins consist of bands associated with the peptide main chain, aromatic side chains, or sulfur containing side chains. Generally, RS is preferred to measure the protein-NP complexes in aqueous solution; moreover, Raman spectra are more simple than IR spectra since the localized vibrations of double or triple bonds or electron-rich groups produce more intense bands than the vibrations of a single bond or electron-poor groups. ${ }^{41}$

- Nuclear magnetic resonance (NMR) spectroscopy. As is well known, the phenomenon of nuclear magnetic resonance can provide detailed information about the structure, dynamics, reaction state, and chemical environment of molecules. The application of NMR to PC characterization allowed residue-specific structural information regarding the adsorbed protein to be obtained. In particular, localized conformational information was obtained regarding some adsorbed peptides, especially by means of solid-state NMR. ${ }^{44}$ 
- Differential scanning calorimetry (DSC) spectroscopy. DSC measures the heat change associated with the thermal denaturation of a molecule when heated at a constant rate. In this way, DSC measures the enthalpy change $(\Delta H)$ of unfolding that results from heat-induced denaturation. Thus, information on protein stability after the NP-adsorption process can be highlighted. ${ }^{47}$

- Fluorescence correlation spectrometry (FCS). This technology can be used to get information about the protein conformation since the maximum level in fluorescence emission spectrum intensity changes correspondingly to the protein conformation. ${ }^{48}$

\section{Composition}

The identities of the proteins composing the corona around NPs can be investigated using techniques such as gel electrophoresis [sodium dodecyl sulfatepolyacrylamide gel electrophoresis (SDS-PAGE) and two-dimensional gel electrophoresis (2-DE)] and mass spectrometry (MS).

It must be underlined that these techniques can be performed only ex situ, after isolation of the NPPC complexes from excess plasma or serum.

- One-dimensional gel electrophoresis (1-DE or SDS-PAGE). In SDS-PAGE, the protein mixture is separated depending on molecular weights after exposure to an electric field. The proteins migrate through a polyacrilamide gel and are separated according to their size due to their different electrophoretic mobilities. Proteins must be previously denatured and negatively charged by an anionic detergent (SDS). After the migration, the proteins can be stained using different methods, such as Coomassie brilliant blue or silver nitrate staining. Densitometry analysis can be performed in order to quantify protein abundance. Molecular weights of separated proteins can be extrapolated by comparing the position of the protein bands with SDS-PAGE profile of a protein molecular weight marker. This technique is often followed by mass spectrometry analysis to determine the identities of the separated proteins. ${ }^{41}$

- Two-dimensional gel electrophoresis (2-DE). This technique separates protein samples in two steps or dimensions. In the first dimension of 2$\mathrm{DE}$, named isoelectric focusing (IEF), proteins are separated accordingly only to their IEP. In the second dimension, SDS-PAGE, proteins are fractionated on the basis of their molecular weights. The bands are then visualized through a staining method and analyzed for protein quantification. ${ }^{49}$ This technique also allows protein identification, since a $2-\mathrm{DE}$ gel can be compared to the 2-DE map of proteins. $32,33,49,50$

- Mass spectrometry (MS). MS has been widely applied to identify the proteins of the corona.

In protocols present in the literature, ${ }^{51-53}$ proteins need to be first digested into smaller peptides with a proteolytic enzyme such as trypsin, in order to reduce the size of the analytes and to produce more suitable data in agreement to the mass range of the instrument. These peptides are ionized in the ion source and then introduced into a region of high vacuum. Ions are separated in function of their mass to charge ratio $(\mathrm{m} / \mathrm{z})$ under either a strong electromagnetic field or in a long drift tube. The resulting mass spectra allow the primary sequence of each given peptide in the mixture to be determined. These data are then compared against the database of the species used in the experiment to recover the protein identities. ${ }^{41}$ With this procedure, MS was applied to identify NP PCs using gel- and non-gel-based methodologies.

Gel-based techniques require, as first step, a protein separation on SDS-PAGE: in more details, the bands of interest are cut from the gel and digested by trypsin, and then the peptides are analyzed by mass spectrometry. This technique was widely employed in order to determine the protein pattern of the whole PC around NPs. ${ }^{23,24,54}$

On the other hand, the non-gel-based method can be applied either on proteins still adsorbed onto the NPs or after protein desorption. The proteins are digested by trypsin and the resulting peptides are directly analyzed by means of MS. Before trypsin digestion, protein denaturation is always performed in order to make the domain for trypsin more accessible.

Overall, both non-gel and gel-based methods require separation of the peptides before the MS injection, exploiting, for example, liquid chromatography. ${ }^{41}$ Several approaches were therefore proposed to this aim: nanoscale liquid chromatography-quadrupole time-of-flight MS/MS (nLC Q-TOF MS/MS), nanoelectrospray liquid chromatography-tandem mass spectrometry (nLC-MS/MS), nano-liquid chromatography MALDI-TOF/TOF, ion trap-mass spectroscopy (ITMS) and matrix-assisted laser desorption/ionization time-of-flightsecondary ion mass spectrometry (MALDI-TOF-SIMS). ${ }^{23,24,26,36,55-57}$ 
TABLE 2 | Schematic Illustration of the Main Techniques Used for the Characterization of Different PC-Related Parameters

\begin{tabular}{|c|c|}
\hline Parameter & Technique(s) \\
\hline \multirow[t]{3}{*}{ Structure/thickness } & Dynamic light scattering (DLS) \\
\hline & Differential centrifugal sedimentation (DCS) \\
\hline & Transmission electron microscopy (TEM) \\
\hline \multirow[t]{3}{*}{ Protein quantification } & Bicinchoninic acid (BCA) assay \\
\hline & Bradford assay \\
\hline & Thermogravimetric analysis (TGA) \\
\hline \multirow[t]{8}{*}{ Binding affinities/stoichiometry and NP-protein interaction } & Fluorescence quenching titration \\
\hline & Fluorescence correlation spectroscopy (FCS) \\
\hline & Size exclusion chromatography (SEC) \\
\hline & Isothermal titration calorimetry (ITC) \\
\hline & Surface plasmon resonance (SPR) \\
\hline & Quartz crystal microbalance (QCM) \\
\hline & Zeta potential (Z-pot) \\
\hline & Computer simulation \\
\hline \multirow[t]{6}{*}{ Protein conformation } & Circular dichroism (CD) \\
\hline & Fourier-transform infrared (FTIR) spectroscopy \\
\hline & Raman spectroscopy (RS) \\
\hline & Nuclear magnetic resonance (NMR) \\
\hline & Differential scanning calorimetry (DSC) \\
\hline & Fluorescence correlation spectrometry (FCS) \\
\hline \multirow[t]{4}{*}{ PC composition } & Sodium dodecyl sulfate-polyacrylamide gel electrophoresis (SDS-PAGE) \\
\hline & 2D-PAGE \\
\hline & Mass spectrometry (in-gel method) \\
\hline & Mass spectrometry (non-gel method) \\
\hline
\end{tabular}

$\mathrm{NP}$, nanoparticle; PC, protein corona.

In summary, the discussed techniques for the investigation of the PC are listed in Table 2.

\section{TECHNICAL APPLICATIONS IN HARD CORONA STUDY}

Table 3 summarizes the identification of the HC features for different NPs using the methods described in the previous section. From a technological point of view, remarkably, it must be highlighted that $\mathrm{HC}$ analysis necessary requires an ex situ approach. As a first step, the most used method for $\mathrm{HC}$ isolation is the centrifugation, as illustrate in Figure $1 .^{2}$ Generally, it allows the isolation of NP-HC complex, while weakly bound proteins are lost. However, it is important to note that the duration of washing as well as the solution volumes used during the washing steps could impact the final results, and that the most abundant proteins, or protein aggregates, may be recovered after sedimentation at the bottom of the centrifugation tube due to in-correct washing. ${ }^{2,15}$ Only a limited number of papers described the application of different isolation methods such as gel filtration, ${ }^{70}$ size exclusion chromatography, ${ }^{17}$ and magnetic separation ${ }^{14,18,70}$ in order to characterize the HC.

\section{HC Structure and Quantification}

As reported in the literature, after the removal of the $\mathrm{SC}$, it is possible to analyze the HC in terms of thickness or increase in mass percentage. ${ }^{23,58,71}$ The evaluation methods are almost the same independently of the kind of NPs (i.e., inorganic or organic polymeric NPs). For example, Casals et al. noted that the diameter of gold NPs (initially $10 \mathrm{~nm}$ ) changed when incubated in fetal bovine serum. In particular they highlighted that a long incubation time $(48 \mathrm{~h})$ lead to a stable protein coating on the NP surface, which produced an increase in diameter of more than $50 \%$ in respect to the initial diameter. ${ }^{22}$ On the other hand, Monopoli et al. demonstrated that the thickness of the HC in polystyrene NPs could change on the basis of plasma concentrations used in the experiment: a higher plasma concentration leads to a thicker HC $(38 \%$ hydrodynamic diameter increase). ${ }^{24}$ This observation was confirmed by Caracciolo et al. in the case of 1,2-dioleoyl-3trimethylammonium propane/DNA NPs incubated in a concentrated solution of plasma, which led to the detection of a thicker total PC $(31 \%$ of hydrodynamic diameter increase). ${ }^{72}$ All of these measurements were obtained by DLS analysis, the most applied technique in order to identify HC thickness. 


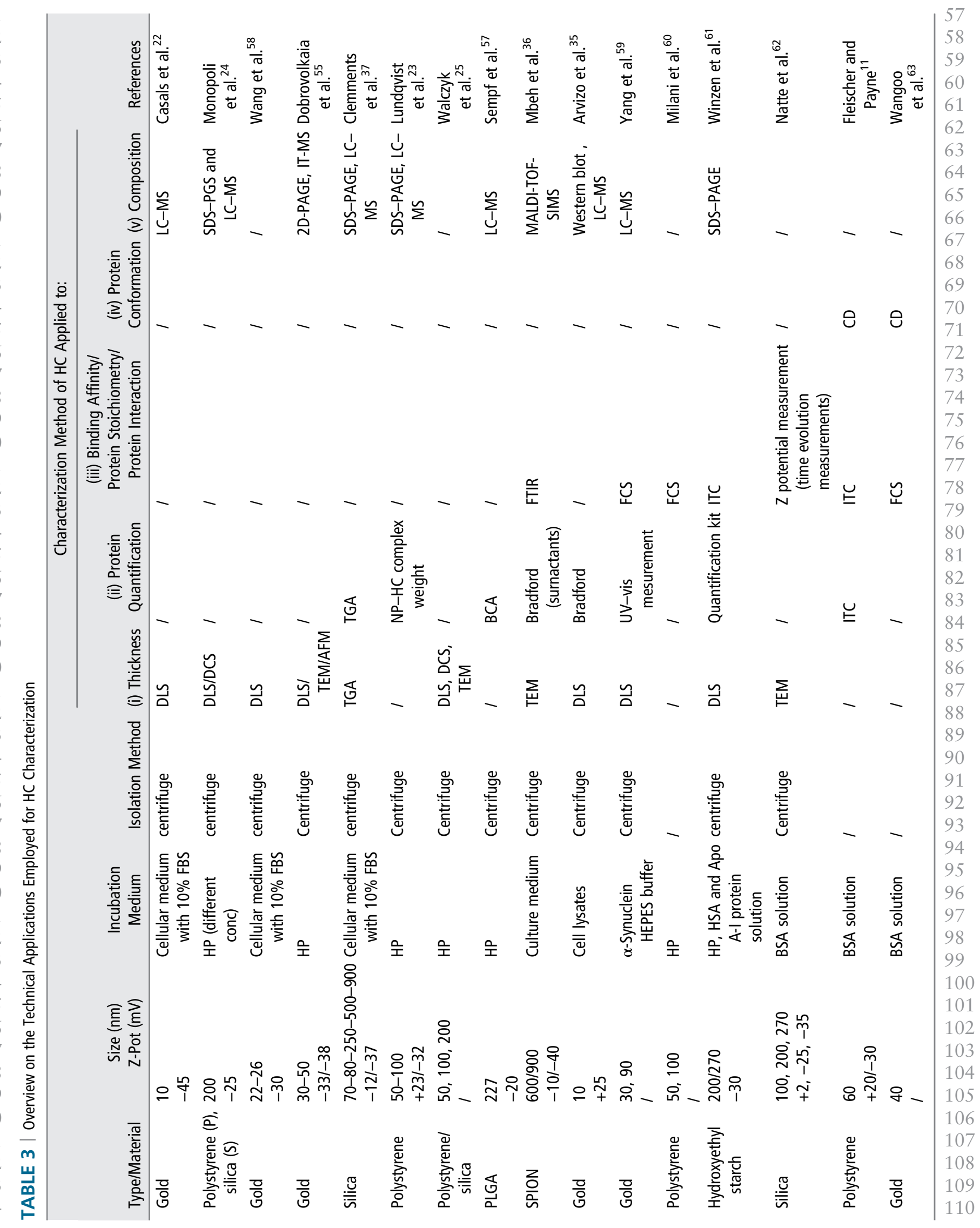




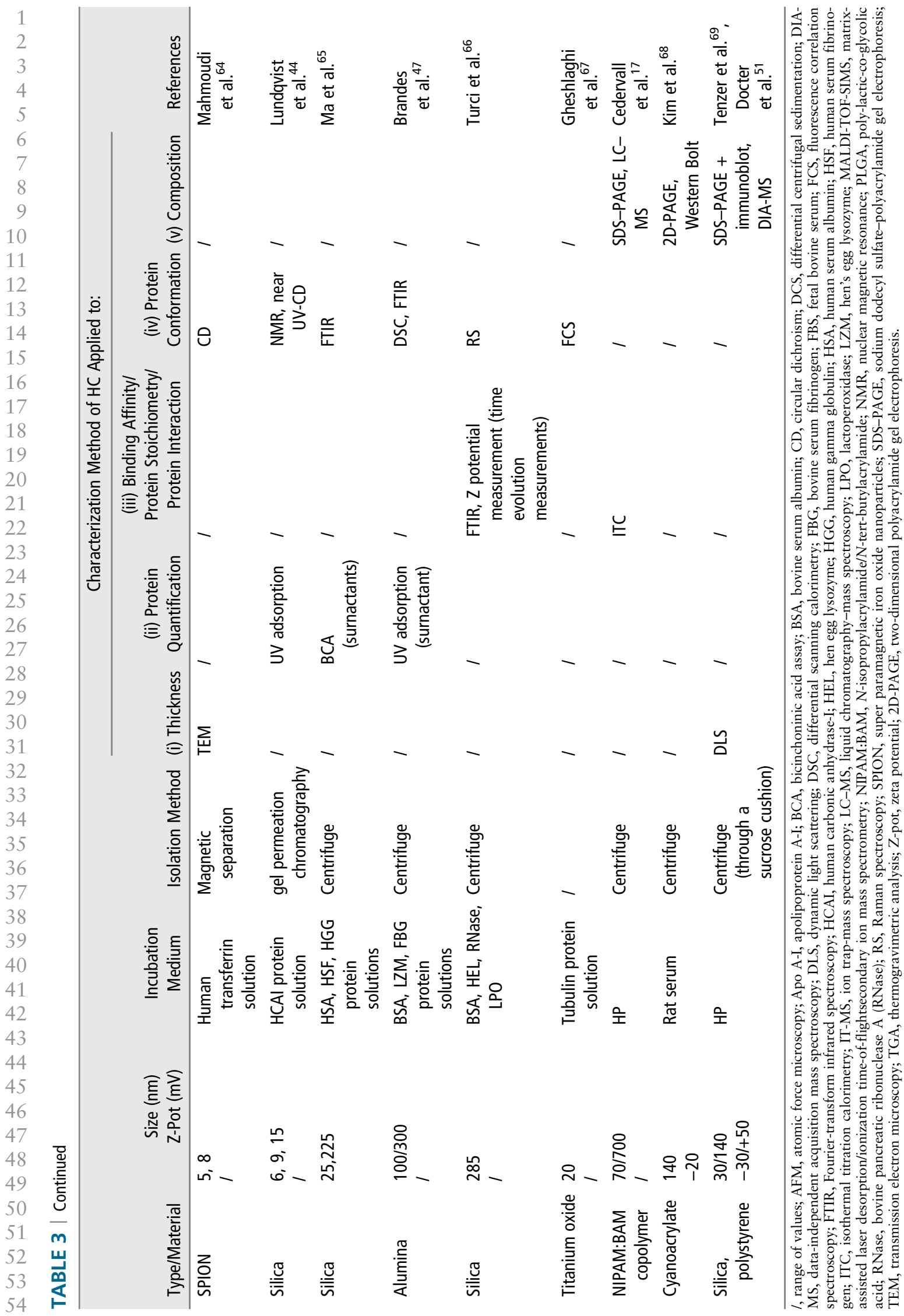




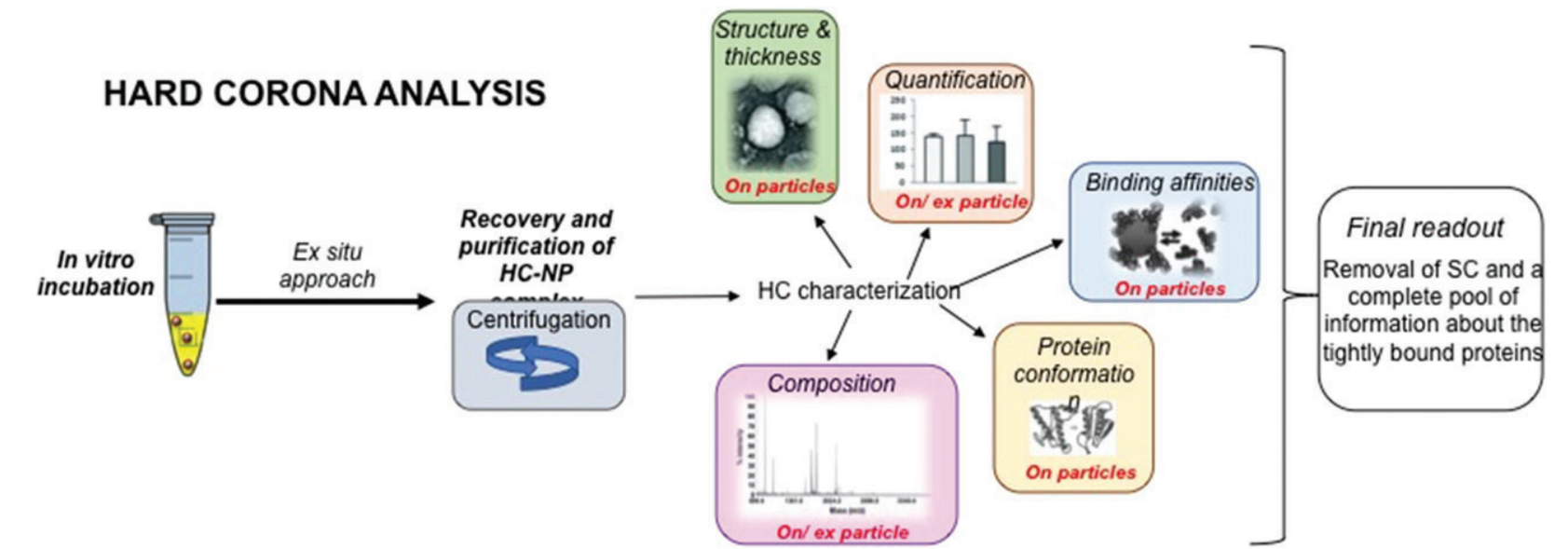

FIG URE 1 | Schematic illustration of hard corona (HC) studies. This kind of analysis requires an ex situ approach (generally by centrifugation). After this first step, the HC characterization is continued with different analytical pathways. Data collected from all these investigations could give a complete pool of information about HC features.

However, it is worth mentioning that centrifugation cycles, performed in order to isolate the HC-NP complex, could lead to aggregation phenomena. Inevitably, these aggregates could dramatically affect the results obtained by DLS and the final thickness should not be considered as comprehensive of the whole sample. As an example, Wang and colleagues observed a change in both size dimension and distribution of gold-NPs after serum incubation; particularly, the average diameter of NPs dramatically increased from 25 to $83 \mathrm{~nm}$ and distribution become more heterogeneous. They hypothesized that the increase in NP diameter was not only due to the formation of $\mathrm{HC}$, but also to the presence of NPprotein agglomerates, caused to the presence of $\mathrm{Ca}^{++}$ and $\mathrm{Mg}^{++}$ions present in the medium. ${ }^{58}$

To complement the information given by DLS, TEM analysis can be applied to furnish structural data, as reported by Walczyk et al. ${ }^{25}$ The authors compared polystyrene NPs before and after plasma incubation, evaluating the dimensions of about 500 NPs for each kind of sample (bare and protein-coated NPs) to reach statistically consistent results. The DLS results indicated that that after plasma incubation, the shell thickness values increased roughly $5-10 \mathrm{~nm}$, but TEM images did not give the same output, as also reported by Dobrovolskaia et al. using gold NPs. ${ }^{55}$ This difference was probably due to the different technology applied; TEM measures NP size on a grid support while DLS evaluate the hydrodynamic diameter of NPs in suspension. However, in this case, TEM analysis was considered useful to prove that plasma incubation did not change the agglomeration state of the NPs and, as a consequence, that DLS analysis was not affected by particle agglomeration phenomena. ${ }^{55}$ This shows the importance that attention must be given to the experimental conditions and especially to the analytical times. $^{73}$

Moreover, the extent of protein coating forming the $\mathrm{HC}$ can be expressed not only as 'thickness values', but also quantitatively. Generally, colorimetric assays are employed (i.e., BCA and Bradford) to measure the $\mathrm{HC}$ protein amount on $\mathrm{NPs}^{36,57}$ or, inversely, the non-adsorbed proteins left in the medium. $^{35}$

Alternatively, Clemments et al. used TGA analysis to characterize the mass percentage of the $\mathrm{HC}$ on their spherical dense/mesoporus silica NPs. In this case, the total amount of adsorbed protein was calculated as a function of weight loss. The data results and reliability of these results are still debatable. In fact, as expected, the smallest particles were found to adsorb the greatest amount of protein, due to the greater surface area (when equal weights of NPs were used). However, by normalizing the total amount of adsorbed protein to the total surface area of each sample, the results clearly stated that an increase in particle diameter greatly increased the amount of adsorbed protein. Thus, the authors hypothesized that a decreased surface curvature of larger particles could favor protein binding, as proteins are able to pack together more closely. ${ }^{37}$

\section{Binding Affinities/Stoichiometry and NP- Protein Interaction}

Data related to the layer thickness of the $\mathrm{HC}$ is frequently reported in scientific researches. $22,24,25,55,58,72,74,75$ On the contrary, the absolute number of bound 
proteins and their exchange dynamics in body fluids are difficult to be assessed with standardized protocols.

In particular, regarding the $\mathrm{HC}$, we are limited by a lack of information on the dynamics of protein exchange, mainly due to a shortage of techniques that allow the assessment of the binding and unbinding of specific proteins to NPs. ${ }^{60}$ To overcome this drawback, Yang et al. elaborated on a two-step fluorescence quenching experiment aiming to quantify the binding affinity of the HC for gold-NPs incubated with a single protein solution [ $\alpha$-synuclein $\left(\alpha\right.$-syn)]. ${ }^{59}$ Briefly, in the first step, different concentrations of gold-NPs were titrated against a known concentration of $\alpha$-syn obtaining the first fluorescence quenching plot. Coated gold-NPs used in this first titration were then collected, purified (by centrifugation) and used in the second titration set against the same amount of $\alpha$-syn (second fluorescence quenching plot). Authors assumed the fluorescence quenching obtained in this second step was the combination of the gold-NPs and SC light absorption. The difference between the first and second florescence plots was then due solely to the HC of $\alpha$-syn on gold-NPs and it was used to calculate HC binding constant.

Alternatively, Milani et al. used FCS to measure $\mathrm{HC}$ binding rate overtime in terms of the number of transferrin molecules bound per particle to sulfonate $(\mathrm{PSOSO} 3 \mathrm{H})$ and carboxyl- (PSCOOH) polystyrene NPs. The authors found that the fraction of molecules (proteins) bound to the NPs could be described with a universal adsorption curve if plotted as a function of molar protein-to-NP ratio. In particular, this adsorption curve was characterized by a two timescale dynamic due to a first strongly bound monolayer (namely $\mathrm{HC}$ ) and to a second weakly bound layer (namely SC). Thus, they demonstrated that the $\mathrm{HC}$ was characterized by an off rate longer than the experimental time scale of a few hours, while the SC appears to exchange proteins within minutes under buffered conditions. ${ }^{60}$

The binding affinity or the exchange rate of the proteins belonging to PC are generally investigated in a comparative manner; this method does not imply a clear distinction between HC and SC, but it allows bound proteins to be ordered on the basis of their affinity to the NPs. As an example, a recent study by Winzen and co-workers applied ITC to characterize PC binding affinity around hydroxyethyl starch nanocapsules. Results revealed large amounts of human serum albumin (HSA) amount present with low binding affinity, probably ascribable to the SC; on the contrary, apolipoprotein A-I was present in small amounts but with high binding affinity, typically considered as a HC component. ${ }^{61}$

In addition, there have also been a huge number of studies evaluating NP-protein dynamics, which provided information not necessarily related to the binding affinity constants. One example assessed the dynamics and evolution of the PC-NPs at different incubation times by evaluating zeta potential values, ${ }^{62}$ zeta potential and $\mathrm{QCM},{ }^{43}$ or by zeta potential and SPR analysis. ${ }^{22}$ In the latter case, depending on time of incubation, SPR measurements shifted over time thus, revealing the formation of a dense dielectric layer around gold NPs due to the adsorption of proteins onto the NPs surface. ${ }^{22}$

\section{Protein Conformation in the $\mathrm{HC}$}

Curved NP surfaces in comparison with planar surfaces are known to be able to provide extra flexibility and enhanced surface area to the adsorbed protein molecules. ${ }^{76}$ However, only in the recent years has the attention focused on the impact of different NPs surfaces 'architectures' on protein conformation. In particular, curved NP surfaces were demonstrated to affect the secondary structures of proteins, and, in some cases, causing irreversible changes. ${ }^{77}$ This phenomenon is particularly relevant when considering the biological fate of NPs, due to obvious implications for clearance and immunological responses. Thus, a number of studies have attempted to investigate on the conformational changes of the proteins adsorbed onto NPs. All the studies referred to the proteins composing the HC layer, the structure closest to nanomaterial, which are affected by modifications of secondary structures in function of surface changes. Aiming to use CD spectroscopy to investigate the interaction of polystyrene NPs with cellular receptors after adsorption of BSA, Fleischer and Payne demonstrated that the secondary structure of adsorbed BSA is strongly responsible for the interaction of the complexes with the receptors. ${ }^{11}$ Also, Wangoo et al. performed CD experiments and found that BSA undergoes to conformational changes in a dose dependent manner when incubated with gold NPs. ${ }^{63}$ Mahmoudi et al. used the same technology to study the interactions of iron saturated human transferrin protein with both bare and polyvinyl alcoholcoated superparamagnetic iron oxide nanoparticles (SPIONs). ${ }^{41}$ In this case, the exposure of human transferrin to SPIONs led to a protein conformational change, from a closed to open conformation, causing the release of iron by the protein. This new conformational state was also maintained after the 
removal of the magnetic nanoparticles indicating the changes in transferrin structure were irreversible. ${ }^{41}$

As a general consideration, CD technology can be considered a powerful analytical tools in determining the protein conformation in solution or when adsorbed onto other structures. This is confirmed by the large number of studies reporting CD spectroscopy to study protein conformational changes. However, data coming from CD analysis can be supported by other analytic methods such as NMR. ${ }^{44}$ For example, Lundqvist et al. studied the conformational change of the protein HCAI adsorbed onto the surface of silica NPs. Through NMR and near-UV CD, the authors were able to demonstrate that longer incubation times correlated with a gradual shift of the native HCAI to a more disturbed conformational form. ${ }^{44}$

Another technique often employed in the determination of protein conformation is represented by FTIR. In a recent work, Ma et l. $^{72}$ used FTIR to investigate the adsorption of human albumin (HSA), globulin (HGG), and fibrinogen (HSF) onto different kinds of mesoporous silica nanoparticles (MSNs). The authors found that the conformation of absorbed HSA and HSF is affected by the pore size and morphology of their MSNs; on the contrary, HGG conformation was not affected by adsorption. Moreover, these conformational changes of the adsorbed proteins were able to affect the saturated adsorption capacity of the NPs. ${ }^{65}$ In another research, the FTIR method was employed in association with highly sensitive DSC to determine adsorption-induced structural changes of the same model proteins [BSA, lysozyme (LZM) and fibrinogen (FBG)] on different ceramic nanoparticles. In almost all cases, protein adsorption resulted in destabilization and structural loss of the bound proteins. In particular, a loss in $\alpha$-helical structure seemed to be the most sensitive structure on adsorption-induced rearrangements. Moreover, the authors conclude that the two techniques applied in the study (DSC and FTIR spectroscopy) were able to provide complementary information on adsorption-induced structural changes. Specifically, DSC was identified as the most suitable technique in order to provide information about the molecular level (thermal stability, overall structure) while FTIR gave relevant information on the sub-molecular level (secondary structure). ${ }^{47}$

Alternatively, Raman spectroscopy (RS) can be used to evaluate the occurrence of conformational changes. Recent experiments revealed that a significant shift of the amide-I band could be observed after incubating silica NPs with a BSA protein solution, whereas, other model proteins maintained their native conformations, after adsorption onto the surface of the NPs (RNase and HEL), under the experimental conditions employed. ${ }^{66}$

Apart from the structural information obtained by CD, FTIR, NMR and RS analysis, some indications about protein conformation changes can be achieved by using FCS. Some authors exploited FCS to investigate the effect of titanium dioxide $\left(\mathrm{TiO}_{2}\right)$ NPs on microtubules polymerization since the tubulin is able to produce a fluorescence quenching and a blue shift of the maximum emission wavelength after the incubation with $\mathrm{TiO}_{2}$ NPs. As evidence, the authors concluded that $\mathrm{TiO}_{2}$ NPs were able to inhibit tubulin polymerization, thus confirming that NPs lead to protein function alteration by inducing changes in protein folding. ${ }^{67}$

\section{HC Composition}

In order to detect the composition of the $\mathrm{HC}$, after isolating the NP-HC complex from the excess of protein in the media, a preliminary desorption process of the proteins from the nanomaterial surface, generally named 'ex-particle' protocol, can be required. Protein desorption from the nanomaterial can be performed by treating the HC-NPs complex with high temperatures, high salt concentrations or detergents to detach them from the complex and make them suitable for the analysis (protein electrophoresis or enzymatic digestion followed by MS). Alternatively, the 'on-particle' protocol can be adopted to by-pass the desorption procedure, but it requires an enzymatic digestion performed on NP surface. This method is particularly useful when the strength of the interaction between the protein and the nanomaterial could cause a partial detachment during desorption leadingto unsatisfactory results.

Generally, the protein desorption method of choice must take great account into the final aim, the technical procedures which are compatible with the samples, the raw materials and the experimental features.

Sempf et al. $^{57}$ chose to apply an 'on particle' approach to the analysis of the HC formed on polylactic-co-glycolic acid (PLGA)-NPs after incubation in human plasma. The proteins were directly digested on the NP surface using trypsin and then analyzed by nLC MALDI-TOF/TOF (without gel analysis). ${ }^{57}$ The authors identified 15 proteins in the HC, 7 of which were not typically abundant in plasma. Moreover the authors compared their results with those obtained by other authors ${ }^{49}$ using other methodologies to investigate the HC of PLGA-NPs. The results were strikingly different within the two experimental sets, 
particularly regarding the presence of proteins such as albumin, Apo A-1, Apo A-4, Apo C-3, and transferrin. Maybe, as explained above, these differences could be ascribable not only to the features of the NPs (size, surface curvature, etc.) but also to the applied analytical method (on-particle vs ex-particle digestion/in-gel vs non-gel approach).

Other papers described the combined method of SDS-PAGE followed by $\mathrm{MS}^{23,24,37}$; one of the most complete work dealt with the detection and evaluation of the HC of NIPAM-BAM NPs with varying sizes $(70-700 \mathrm{~nm})$ and polymers ratios, finally identifying HSA, apolipoprotein A-IV, apolipoprotein A-I and apolipoprotein A-II as the most consistently present proteins composing the $\mathrm{HC}$ around these NPs. ${ }^{26}$ Another research group employed 2D-PAGE and Western blotting analysis to compare the HC profile of pegylated- polyhexadecylcyanoacrylate (PHDCA) NPs to non-pegylated PHDCA-NPs. The results revealed that, after incubation with rat serum, apolipoprotein $\mathrm{E}$ (ApoE) adsorbed more onto PEG-PHDCA than on PHDCA nanoparticles. ${ }^{68}$

As also remarked by Walkey and Chan, some proteins adsorb abundantly to every nanomaterial, while other proteins do not. The abundant proteins in the HC are not always the same and it is strictly dependent on the NP feature and experimental condition adopted. It is also important to note that the total number of unique proteins within the PC of any nanomaterial is unknown. While LC-MS/MS is more sensitive, and tends to detect more low abundance proteins, neither PAGE nor LC-MS/MS is sensitive to the single molecule level. ${ }^{15}$

Interestingly, a recent work proposed an upgraded method by combining SDS-PAGE/MS to obtain time-resolved HC profiles formed on various NPs. ${ }^{51}$ Briefly, after NP incubation in protein containing medium, NP-protein complexes were rapidly separated from unbound proteins by sedimentation through a sucrose cushion, and washed to obtain the HC-NP complex. Subsequently, the protein desorption and separation could be obtained via 1D SDS-PAGE in association with an immunoblot analysis to identify and (semi)-quantify the presence of specific corona proteins. Alternatively, the authors proposed a protocols based on protein desorption and digestion with trypsin followed by resolution of the obtained peptides by high-resolution nanoscale ultra-performance liquid chromatography on reversed-phase (C18) columns, analyzed by ion mobility-enhanced data-independent acquisition (DIA) MS. This complex protocol could give interesting improvements since the sucrose cushion centrifugation method efficiently limits the contact time of NPs with the biological fluid of interest, rendering analyses of short time periods feasible. Moreover, the adapted label-free quantification by LC-MS (taken by the recently described ion mobility-enhanced, DIAbased label-free quantitative proteomics workflow of Distler et al.) ${ }^{78}$ allows reliable and highly reproducible quantification of corona components. Moreover, the authors specified that the protocol could be readily extended to the investigation of PCs from various nanomaterials, as confirmed by the application of this protocol to different silica nanoparticles and polystyrene nanoparticles. ${ }^{51,69}$

\section{TECHNICAL APPLICATIONS IN SOFT CORONA STUDY}

An overview of studies referring to SC characterization is reported in Table 4. In comparison with the HC, a limited number of methods for SC detection are available. As a consequence, poor knowledge concerning the SC is present.

The major drawback is the SC isolation. In fact, the common isolation methods, inevitably, stress the NP-PC complex resulting in a partial, or sometimes total, detachment of the SC. As a matter of fact, almost a totality of studies on the SC relied upon in situ techniques (previously described) and is mostly focused on the identification of the SC structure, with the exclusion of a few exceptionally complex experimental procedures (Figure 2). To-today SC characterization still represents an intriguing challenge.

\section{SC Structure and Quantification}

The major part of studies concerning the SC structure provide the measurement of the total PC thickness depleted of HC contribution. However, this indirect measurement needs to be carefully evaluated in order to avoid unreliable results and therefore, presents several criticisms such as the congruity of time, condition and methods of analysis for total PC and HC thickness. In fact, it is obvious that the comparison between in situ and ex situ measurements could provide only an approximation regarding the SC structure since it is not possible to compare measurements performed in a suspension medium with a different diffraction index, a concept often neglected in some PC studies. ${ }^{22}$ Considering this gap, a clear study of the SC structure and thickness only by DLS analysis is not an easy thing to manage. Schaffler et al. tried to by-pass this gap by incubating gold NPs in a diluted serum solution (1:100 in PBS buffer). ${ }^{79}$ With this protocol, the measurements performed in situ are more comparable with the measurements performed 


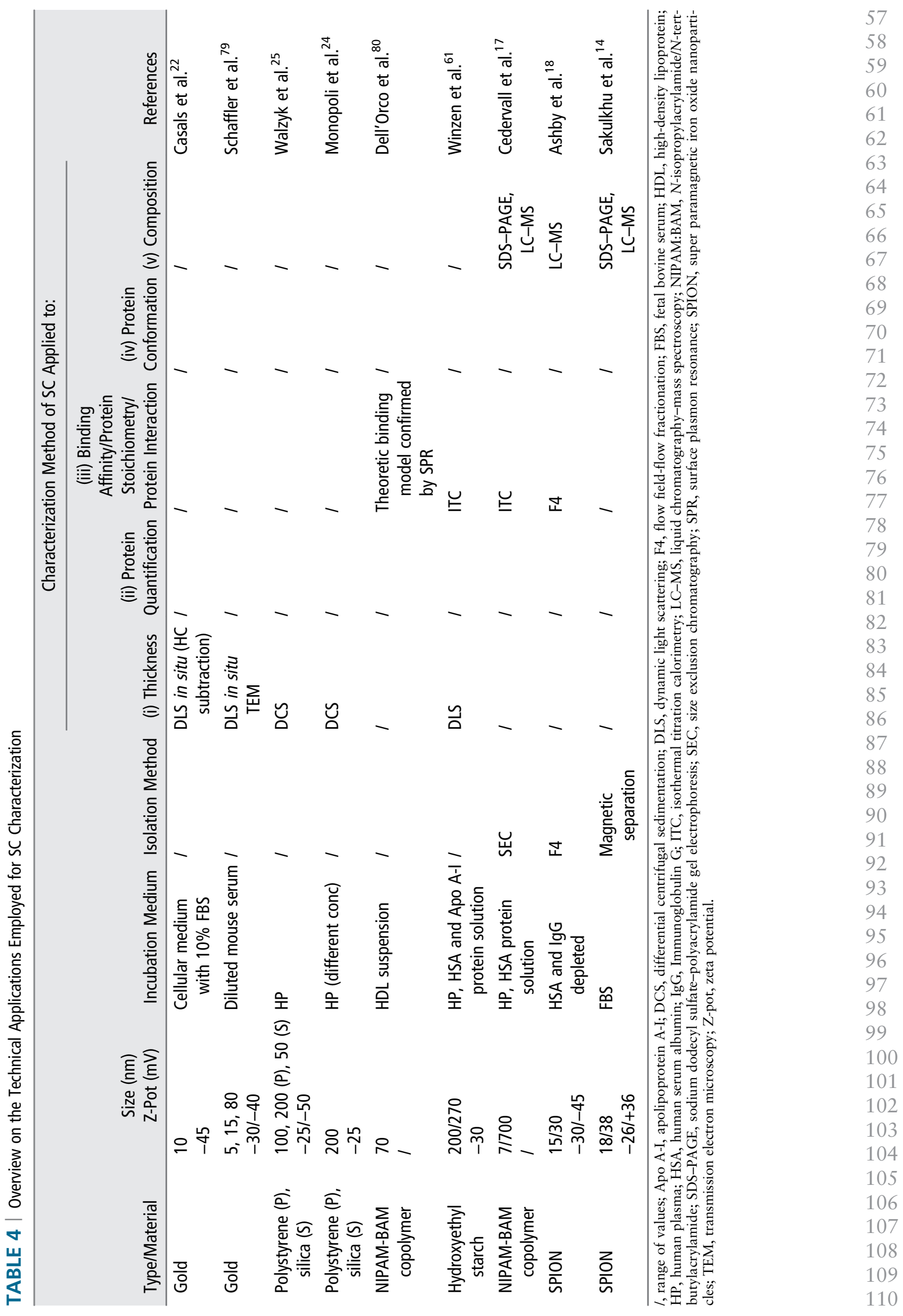




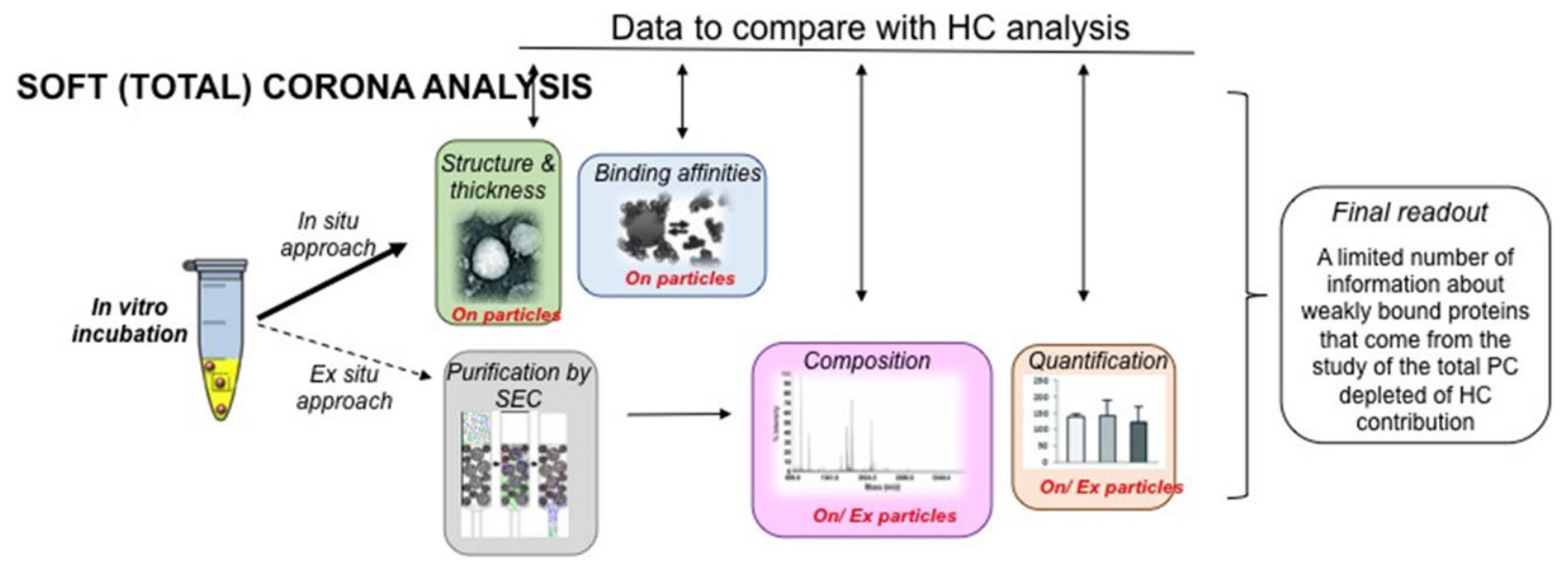

FIGURE 2 | Schematic illustration of soft corona (SC) studies. The major part of the studies are based on in situ approach (solid black arrow), with the exception of a few cases based on ex situ approach (dashed arrow). The information given by the SC analysis are more limited or completely missing in number if compared with $\mathrm{HC}$ analysis (if considering protein conformation analysis). Moreover, SC data are generally obtained by the measurement of the total PC subtracting the HC (as indicated by the double arrows in the upper part of the scheme).

after the centrifugation and re-suspension procedures. The data obtained from the incubation in situ experiment showed an increased hydrodynamic diameter of the gold NPs; this increase remained unchanged even after centrifugation and re-suspension. The lack of size reduction after centrifugation is interpreted as a technical limit of DLS in measuring the labile part of the PC (alias SC), as only the HC was detected before and after the purification processes.

Thus, in this case, DLS analysis is not strongly affected by different incubation media diffraction indices of, but the incubation in diluted plasma could lead to an incomplete coverage of proteins around the NPs. In fact, total plasma incubation better simulates the in vivo conditions that give a large excess of proteins occurring to saturate the surface of NPs, while a deficit of protein concentration in the incubation medium can explain the behaviour of gold NPs.

DCS represents the other mainly elective method to study the SC; with respect DLS, the DCS technique is limited by the requirement of applying a mathematic model. For example, aiming to identify a reliable size by DCS, one must know the shape and internal density distribution of each aggregate. To overcome this problem, researchers present their data by correlating the equivalent diameters for spheres of homogeneous density and relative 'apparent' molecular weight. ${ }^{25}$ Thus, the 'true' size of the NP-protein complex and the corona size were computed on monomeric NPs-protein complexes using a simple coreshell model of two densities (bare particle material density and adsorbed protein-biomolecule density). This core-shell model is generally the most used for these experiments. ${ }^{81,82}$ It is a simple model to analyze data for shell-coated particles and to get an estimation of the shell thickness. In this case, the shell is represented by the PC. In this study, the PC of polystyrene NPs was measured under several different conditions including full plasma (diluted in PBS), after washing, centrifugation, and re-suspension in PBS buffer, thus enabling washing-off of the excess (unbound or loosely bound) proteins. In the presence of excess plasma, these different experimental conditions allowed the authors to draw connections between the $\mathrm{NP}$-corona complexes in isolation and in situ, to finally refer to the presence of the SC. The DCS method was applied in the experiment on both silica and polystyrene NPs after plasma incubation. ${ }^{24}$ Interestingly, after centrifugation no difference in NP size was reported, but only a reduction of the PC thickness, inversely proportional to the plasma concentration, was observed.

Overall, the experiments described above clearly showed that, independent of the NP characteristics (material composition, size) and incubation conditions (time and temperature), both techniques (DLS and DCS) are able to describe the increase in NP diameter after plasma incubation. However, discriminating between $\mathrm{HC}$ and SC is not always so clear. In opposition with Casal's work, Schaffler's group declared the impossibility to measure the SC by DLS. ${ }^{79}$ Other researchers ${ }^{25}$ tried to calculate the SC contribution in PC thickness by an indirect method in which the diameter of the HC, calculated by core-shell model, was subtracted from the total diameter is measured by DCS; in this experiment, data seemed to support the efficacy of DCS method for SC structure determination. 
Generally, the experimental data related to SC analyses appear discordant, and the differences in the definition of the SC (as debated above in paragraph 2 ) strongly generate confusion and, as a consequence, different manners of interpreting the data. Similarly, the discrepancy of results concerning the SC is certainly due to the lack of a fine method of detection, able to appreciate slight differences in terms of size as well as to monitor the quickly evolving and mutable binding states of the SC. Moreover, it is interesting to note that the major part of this investigation on SC structure belongs to experiments on inorganic NPs such as SPION, silica and gold NPs. The major dispersion in size distribution of organic polymeric NPs is probably one of the critical point that limits PC studies on these particles; data relating their in vivo behaviour are poor or totally lacking. Researching a reliable method to discriminate the SC contribution to the total PC structure is actually an urgent issue, especially for organic polymer NPs.

\section{Binding Affinities and Stoichiometry of Proteins in the SC}

The binding and dissociation rates of proteins to NPs are surely critical parameters for their biological fate. It is widely accepted that the tightly associated proteins of the $\mathrm{HC}$ (with slow exchange rate) may follow the particle during the endocytosis process, while proteins of SC (with fast exchange rate) are quickly replaced by the intracellular proteins, during or immediately after endocytosis. ${ }^{83}$ As a consequence, the SC is generally considered less relevant in governing the functional response of NPs. However, the biological outcome may differ if, not only endocytosis process, but also the relative protein exchange rates between NPs and cellular receptors, are considered. Because the protein-ligand complexes typically display lifetimes from microseconds to days, ${ }^{17}$ it is feasible that the fast exchanging proteins of the SC could be strongly involved in determining the biological fate of a NP, even if the rates of association and dissociation are likely to vary quite considerably depending on the protein and particle type.

As previously reported, methods are generally oriented to compare the protein exchange rates of the total PC; in this paragraph, we principally discuss studies dealing with protein binding affinity in the total corona, as the discrimination for SC proteins could only be hypothesized from the total PC analysis.

In this way, a mathematical dynamic model was developed aiming to predict the time evolution and equilibrium composition of the total PC based on protein affinities, stoichiometries, and rate constants. The authors applied both the theoretical model and experiment procedures (by SPR technique) to polymeric NPs (NIPAM/BAM) interacting with three model proteins [HSA, high-density lipoprotein (HDL) and fibrinogen]. Experiments indicated that the PC evolves with time (as predicted by the model), with evidence of HSA presence in the SC and HDL presence in HC. ${ }^{80}$ These findings nicely correlated with the results previously described on the characterization of the PC binding affinity, where HSA showed low binding affinity (ascribable to the SC) around hydroxyethyl starch nanocapsules. ${ }^{61}$

Moreover, the protein binding affinity study can be helpful to describe how some NP features could affect the protein exchange rate of the PC. In an elegant study, Cedervall et al., using SEC and ITC techniques, investigated the impact of different copolymer ratios and different rates of hydrophilicity/ hydrophobicity of NIPAM-BAM NPs on the association and dissociation of HSA and fibrinogen. Results suggested that protein dissociation is affected by the surface properties of NPs (exposition of functional groups, hydrophilic/hydrophobic surface balance) and in particular, dissociation was faster considering the hydrophobic particles. ${ }^{17}$

However, most of the kinetic modeling of corona complex formation is operated through in silico studies. Mathematical modeling helps to learn principles and to develop quantitative approaches that cannot be experimentally extracted. Moreover, mathematical models provide quali/quantitative endpoints, useful for the design and evaluation of experiments. In this view, different approaches in the literature are proposed. For example, Darabi Sahneh et al. presented a model to describe two-phases of corona complex dynamics, based on two formulae that predict corona composition of simulations through insertion of appropriate parameters depending on features of the NPs. ${ }^{84}$ The authors assert that one potential application of this model would involve a single cell culture medium related to a complex protein medium, such as blood or tissue fluid. On the contrary, Vilaseca et al. simulated molecular dynamics to study the surface adsorption of proteins. The authors reduced the complexity of a full modeling by approximating protein molecules as single, rigid entities. Kinetic modeling of the corona complex formation process dramatically decreases computational cost, though adopting several simplifying assumptions. Finally, in silico analysis can be applied to predict the final in vivo response of NP-PC complexes. ${ }^{85}$

In silico prediction analyses were also applied to predict the evolution and subcellular distribution 
of NPs in living cells ${ }^{84,86,87}$; the interactions between NP-PC complexes and cellular membranes were investigated showing that the PC may enhance phagocytosis of positively charged NPs, but also cause the loss of targeting activity of both hydrophobic and positively charged NPs towards cancer cells.

\section{Protein Conformation and Composition of the SC}

As previously reported, the studies on protein conformation are all referred to the HC. In the SC, the proteins, loosely bonded to the NPs surface or displaying weak interaction with $\mathrm{HC}$, are characterized by a fast dissociation rate, making the detection and full characterization of structural changes particularly difficult. Similarly, only a few papers describe the composition of the SC and generally, complex experimental procedures are required to recognize the proteins involved.

Ashby et al. (2013) presented an alternative method to analyse the SC consisting of the flow fieldflow fraction (F4) technique. ${ }^{18}$ Upon incubation with depleted serum (human serum without albumin or IgG), half of the NPs were centrifuged for coprecipitation of 'all' bound proteins. The other half was injected on the F4-column to remove proteins bound with fast exchange kinetics (SC), thus leaving only the proteins bound with slow exchange kinetics (HC) to be co-isolated with the SPIONs. The proteins collected with the SPIONs were digested and analyzed by two-dimensional PAGE and nano-LC-MS/ MS for identification. Through mass identification of the total protein after NP-PC complex centrifugation and subtracting the protein identified on the surface of the NPs after F4-column elution, the authors supply a list of proteins characterizing the SC.

Surely, this method permits the discrimination of those proteins binding with fast exchanging kinetics, belonging to the SC, but on the other hand it appears debatable that 'all' the proteins forming the $\mathrm{PC}$ can be isolated by centrifugation. Confirming this lack of clearness, other authors assessed that centrifugation of the NP-PC complex inevitably leads to a perturbation of the system and, as a consequence, to the partial loss of the loosely binding proteins. ${ }^{17,88}$

Alternatively, Sakulkhu et al. proposed a different approach regarding SPION-PC characterization. After the incubation of NPs in serum, SPIONs surrounded by the PC were entrapped into a magnetic column and the protein was eluted by means of various buffers with different ionic strengths, in order to separate the proteins from the NPs. ${ }^{14}$ In particular, to investigate the $\mathrm{SC}$, the researchers applied a first wash with PBS to separate loosely bound proteins, followed by washes with solutions of up to $2 \mathrm{M} \mathrm{KCl}$. Finally, those proteins which remained bound to the NPs were called 'tightly bound' proteins. In this way, the final result is a triple partition of the total PC: SC, HC and 'tightly bound'. Each elution fraction was analyzed by SDS-PAGE coupled to LC-MS/MS to protein identification. This technical strategy allowed for a fine characterization of the whole PC in general, but in particular, permitted the investigation of the SC composition. Indeed, the magnetic separation technique and the magnetic properties of SPIONs are useful to overcome problems of SC isolation in order to characterize its composition, but, on the other hand, this technique can inevitably only be appreciated for a few fields of application. The obtained results, reported in the article, showed that 'tightly bound' proteins were observed only on negatively charged PVA-coated SPIONs after the strong protein elution. The triple partition of total PC represents a novelty in this research field and, one more time, is proof of the great confusion about appropriately defining the PC. Nevertheless, the work of Sakulkhu et al. is well organized; no parameters exist to establish what are the HC, SC and 'tightly bound' proteins. Thus, the triple partition of the article results are arbitrary and non-comparable with other articles in which only a bi-partition of the total PC is present. $^{81}$

Apart from SPIONs, the only characterization attempt for SC composition can be ascribed to Cedervall et al. ${ }^{17}$ Using SEC, researchers were able to distinguish both fast and slow components of the PC (as discussed above in relationship with binding affinity of SC proteins). Furthermore, they also were able to collect the proteins with fast exchange rate (ascribable to the SC) and characterize them through SDS-PAGE. In this manner, they compared the NPassociated protein received after centrifugation and after SEC isolation. In particular, through SEC protein isolation, they found that HSA and fibrinogen concentrations dominate on the particle surface. On the contrary, apolipoprotein A-I (a lower plasma abundant protein with higher affinity and slower kinetics ascribable to the $\mathrm{HC}$ ) was the most abundant protein recovered after centrifugation. ${ }^{17}$

\section{INSIDE THE METHODS: LIMITATIONS AND ADVANTAGES}

Aiming to analyse the HC composition, the choice between ex-particle or on-particle approaches still remain an open issue. As confirmation of this 
1 uncertainty, some authors described some defects 2 and limitation of the ex-particle approach, especially if the proteins are only identified by 2D-PAGE after the desorption step. ${ }^{57}$ In their opinion, the ex-particle approach can easily allow a sample contamination by albumin (the most abundant protein in plasma). Furthermore, 2D-PAGE bases protein identification on the comparison of the respective spot positions with a standard reference map. This methodology may lead to misinterpretation of the data due to spots overlapping, especially with complex proteomes, like human plasma. Besides this limitation, it is true that the ex-particle method allows better sample fractionation as well as multiple analyses (i.e., electrophoresis tandem-mass spectroscopy) that lead to a major number of recognized proteins.

So, the main drawback on HC analysis is not regarding the kind of approach (on-particle or exparticle), but how to obtain a solid result independently from the chosen approach. In this way, a multiple-technique protocol (i.e., electrophoresis + mass spectroscopy, or chromatography + electrophoresis) can represent a good solution.

Beside this aspect, the overlap of different techniques of investigation and advances in instrument technologies and software has allowed to reach an earlier mapping of the HC of different NPs on the basis of size and material composition. There are review-tables in which it is possible to recognize different type of NPs and the related identified proteins of the HC. ${ }^{89}$ One of the most important aspects and findings is the reproducibility of the data on comparable NPs exposed to similar incubation condition showing comparable results in terms of the $\mathrm{HC}$ composition.

Regarding the SC analysis method, a shortage of investigative methods and, as a consequence, shortage of available data concerning the SC, does not allow speculation on the weakness and strengths of the analysis and of the resulting data. In particular poor specificity, low reproducible rate of results and poor applicability-range of some techniques designed 'ad hoc' for specific typologies of NPs represent the most important limitations.

Finally, it is worth to mention that almost all the studies concerning $\mathrm{HC}$ and SC have been carried out in vitro. This is mainly due to the difficulty of capturing NPs after administration. Nevertheless, the importance to understand structure-activity relations linking NPs and proteins adsorbed on their surface to physiological responses is needed for effective biomedical application of NPs. Improving the ability to predict the biological outcomes of NPs will speed up their translation to the clinic. As a matter of facts, the recognition of specific sequences of peptides drives key biological processes, such as receptormediated cellular association, particle retention in tissues and organs, and ability (or inability) to cross biological barriers. To date, we are still unable to decipher the mechanisms regulating the interaction between PC-covered NPs and biological systems and more studies are needed. Deciphering the biological recognition between PC proteins and cell receptors could help us understand exactly how proteindecorated NPs interact with cells and biological barriers, potentially activating different biological pathways. $^{90}$

\section{CONCLUSION AND FUTURE PROSPECTIVE}

The last 20 years of research in nanomedicines have taught us that the composition of the nanoparticle itself was the most important keystone impacting the destiny of NPs. Nowadays, we must be aware that nanoparticles are not only formed by 'polymers and drugs', but are associated with proteins, stably or weakly adsorbed onto their surface. Nanoparticles and their PC are new 'biological entities'.91 These interactions strongly impacts (maybe more than the composition of the nanoparticles, size, and shapes) their safety and functionality performances.

Since this concept is relatively new, a number of issues are now up for debate:

1. Is the physiological response of a nanomedicine (meaning drug delivery system + associated PC) influenced by the whole PC or only a subset?

2. Are the protein belonging to the SC implicated in physiological response or not?

3. Are the technologies suitable and sufficient to discriminate and describe the HC, SC, or both?

4. What competences and skills are needed to completely understand the impact of the PC on the destiny of nanomedicines?

To-date, many of these questions are almost completely unsolved, but some indications and future direction could be hypothesized.

Firstly, it is reliable that the whole PC influences the biodistribution of PC-NPs complexes, but it could be hypothesized that some specific NP tropisms or accumulation could be due to a selective interaction of a subset of the associated PC with specific cells or receptors. 
Moreover, the most debated aspect of the PC 'area' is the role of the SC and HC in determining biological effects. Some authors hypothesize that the $\mathrm{SC}$ is not pivotal in governing the biological destiny of nanomedicines, other authors are fully convinced of the contrary while some others researchers described the role of the SC of a minor importance with respect to the role of the HC.

A clear knowledge of these aspects is critical since it could strongly help in designing nanomaterials able to interact with proteins and cells in a controlled way. ${ }^{92,93}$ As a consequence of the lack of this knowledge, most nanomedicine are created specifically aiming to suppress protein adsorption. This would reduce off-target cell uptake, but also lowers targeting efficiency. ${ }^{94,95}$

Another important lack in PC research is connected with technologies. PC-NPs complexes could be characterized by integrating information on morphology (imaging-spectroscopy-scattering based techniques) ${ }^{41}$ and on structure/composition of the PC (cryo-electron microscopy and protein crystallography). ${ }^{15}$ Thus, multi-disciplinary approaches are needed in order to obtain much more information about the PC and its properties to fully understand the real impact of the PC on nanomedicines, and therefore to better support a more safety and conscious application of nanotechnology in medicine.

\section{ACKNOWLEDGMENTS}

We gratefully thanks to Dr. J. T. Duskey for English revision and also University of Modena and Reggio Emilia for grant FAR 2014 (Single Particle Tracking: nanomedicine and quantum dots) for supporting research.

\section{REFERENCES}

1. Elsabahy M, Wooley KL. Design of polymeric nanoparticles for biomedical delivery applications. Chem Soc Rev 2012, 41:2545-2561.

2. Aggarwal P, Hall JB, McLeland CB, Dobrovolskaia MA, McNeil SE. Nanoparticle interaction with plasma proteins as it relates to particle biodistribution, biocompatibility and therapeutic efficacy. Adv Drug Deliv Rev 2009, 61:428-437.

3. Caracciolo G. Liposome-protein corona in a physiological environment: challenges and opportunities for targeted delivery of nanomedicines. Nanomedicine 2015, 11:543-557.

4. Foroozandeh P, Aziz AA. Merging worlds of nanomaterials and biological environment: factors governing protein corona formation on nanoparticles and its biological consequences. Nanoscale Res Lett 2015, $10: 221$.

5. Gunawan C, Lim M, Marquis CP, Amal R. Nanoparticle-protein corona complexes govern the biological fates and functions of nanoparticles. J Mater Chem B 2014, 2:2060.

6. Karmali PP, Simberg D. Interactions of nanoparticles with plasma proteins: implication on clearance and toxicity of drug delivery systems. Expert Opin Drug Deliv 2011, 8:343-357.

7. Kumar A, Bicer EM, Morgan AB, Pfeffer PE, Monopoli M, Dawson KA, Eriksson J, Edwards K, Lynham S, Arno M, et al. Enrichment of immunoregulatory proteins in the biomolecular corona of nanoparticles within human respiratory tract lining fluid. Nanomedicine 2016, 12:1033-1043.

8. Wolfram J, Suri K, Yang Y, Shen J, Celia C, Fresta M, Zhao Y, Shen H, Ferrari M. Shrinkage of pegylated and non-pegylated liposomes in serum. Colloids Surf B Biointerfaces 2014, 114:294-300.

9. Corbo C, Molinaro R, Parodi A, Furman NET, Salvatore F, Tasciotti E. The impact of nanoparticle protein corona on cytotoxicity, immunotoxicity and target drug delivery. Nanomedicine 2016, 11:81-100.

10. Duran N, Silveira CP, Duran M, Martinez DS. Silver nanoparticle protein corona and toxicity: a minireview. J Nanobiotechnol 2015, 13:55.

11. Fleischer CC, Payne CK. Nanoparticle-cell interactions: molecular structure of the protein corona and cellular outcomes. Acc Chem Res 2014, 47:2651-2659.

12. Lee YK, Choi EJ, Webster TJ, Kim SH, Khang D. Effect of the protein corona on nanoparticles for modulating cytotoxicity and immunotoxicity. Int J Nanomedicine 2015, 10:97-113.

13. Rahman M, Laurent S, Tawil N, Yahia LH, Mahmoudi M. Nanoparticle and Protein Corona, vol. 15. XXX: XXX; 2013, 21-44.

14. Sakulkhu U, Mahmoudi M, Maurizi L, Salaklang J, Hofmann H. Protein corona composition of superparamagnetic iron oxide nanoparticles with various physico-chemical properties and coatings. Sci Rep 2014, 4:5020. 
15. Walkey CD, Chan WC. Understanding and controlling the interaction of nanomaterials with proteins in a physiological environment. Chem Soc Rev 2012, 41:2780-2799.

16. Norde W. Protein adsorption at solid surfaces: a thermodynamic approach. Pure Appl Chem 1994, 66:491-496.

17. Cedervall $\mathrm{T}$, Lynch I, Lindman S, Berggard $\mathrm{T}$, Thulin E, Nilsson H, Dawson KA, Linse S. Understanding the nanoparticle-protein corona using methods to quantify exchange rates and affinities of proteins for nanoparticles. Proc Natl Acad Sci U S A 2007, 104:2050-2055.

18. Ashby J, Pan S, Zhong W. Size and surface functionalization of iron oxide nanoparticles influence the composition and dynamic nature of their protein corona. ACS Appl Mater Interfaces 2014, 6:15412-15419.

19. Simberg D, Park JH, Karmali PP, Zhang WM, Merkulov S, McCrae K, Bhatia SN, Sailor M, Ruoslahti E. Differential proteomics analysis of the surface heterogeneity of dextran iron oxide nanoparticles and the implications for their in vivo clearance. Biomaterials 2009, 30:3926-3933.

20. Lynch I, Cedervall T, Lundqvist M, Cabaleiro-Lago C, Linse S, Dawson KA. The nanoparticle-protein complex as a biological entity; a complex fluids and surface science challenge for the 21st century. $A d v$ Colloid Interface Sci 2007, 134-135:167-174.

21. Sund J, Alenius H, Vippola M, Savolainen K, Puustinen A. Proteomic characterization of engineered nanomaterial-protein interactions in relation to surface reactivity. ACS Nano 2011, 5:4300-4309.

22. Casals E, Pfaller T, Duschl A, Oostingh GJ, Puntes V. Time evolution of the nanoparticle protein corona. ACS Nano 2010, 4:3623-3632.

23. Lundqvist M, Stigler J, Elia G, Lynch I, Cedervall T, Dawson KA. Nanoparticle size and surface properties determine the protein corona with possible implications for biological impacts. Proc Natl Acad Sci U S A 2008, 105:14265-14270.

24. Monopoli MP, Walczyk D, Campbell A, Elia G, Lynch I, Bombelli FB, Dawson KA. Physical-chemical aspects of protein corona: relevance to in vitro and in vivo biological impacts of nanoparticles. $\mathrm{J} \mathrm{Am}$ Chem Soc 2011, 133:2525-2534.

25. Walczyk D, Bombelli FB, Monopoli MP, Lynch I, Dawson KA. What the cell "sees" in bionanoscience. J Am Chem Soc 2010, 132:5761-5768.

26. Cedervall T, Lynch I, Foy M, Berggard T, Donnelly SC, Cagney G, Linse S, Dawson KA. Detailed identification of plasma proteins adsorbed on copolymer nanoparticles. Angew Chem Int Ed Engl 2007, 46:5754-5756.

27. Messaud FA, Sanderson RD, Runyon JR, Otte T, Pasch H, Williams SKR. An overview on field-flow fractionation techniques and their applications in the separation and characterization of polymers. Prog Polym Sci 2009, 34:351-368.

28. Maiorano G, Sabella S, Sorce B, Brunetti V, Malvindi MA, Cingolani R, Pompa PP. Effects of cell culture media on the dynamic formation of protein -nanoparticle complexes and influence on the cellular response. ACS Nano 2010, 4:7481-7491.

29. Fischer K, Schmidt M. Pitfalls and novel applications of particle sizing by dynamic light scattering. Biomaterials 2016, 98:79-91.

30. Mahmoudi M, Abdelmonem AM, Behzadi S, Clement JH, Dutz S, Ejtehadi MR, Hartmann R, Kantner K, Linne U, Maffre P. Temperature: the "ignored" factor at the nanobio interface. ACS Nano 2013, 7:6555-6562.

31. Chutipongtanate S, Watcharatanyatip K, Homvises T, Jaturongkakul K, Thongboonkerd V. Systematic comparisons of various spectrophotometric and colorimetric methods to measure concentrations of protein, peptide and amino acid: detectable limits, linear dynamic ranges, interferences, practicality and unit costs. Talanta 2012, 98:123-129.

32. Gessner A, Lieske A, Paulke BR, Müller RH. Functional groups on polystyrene model nanoparticles: influence on protein adsorption. $J$ Biomed Mater Res A 2003, 65:319-326.

33. Goppert TM, Muller RH. Protein adsorption patterns on poloxamer- and poloxamine-stabilized solid lipid nanoparticles (SLN). Eur J Pharm Biopharm 2005, 60:361-372.

34. Sohaebuddin SK, Thevenot PT, Baker D, Eaton JW, Tang L. Nanomaterial cytotoxicity is composition, size, and cell type dependent. Part Fibre Toxicol 2010, 7:1.

35. Arvizo RR, Giri K, Moyano D, Miranda OR, Madden B, McCormick DJ, Bhattacharya R, Rotello VM, Kocher JP, Mukherjee P. Identifying new therapeutic targets via modulation of protein corona formation by engineered nanoparticles. PLoS One 2012, 7:e33650.

36. Mbeh DA, Javanbakht T, Tabet L, Merhi Y, Maghni K, Sacher E, Yahia LH. Protein corona formation on magnetite nanoparticles: effects of culture medium composition, and its consequences on superparamagnetic nanoparticle cytotoxicity. J Biomed Nanotechnol 2015, 11:828-840.

37. Clemments AM, Botella P, Landry CC. Protein adsorption from biofluids on silica nanoparticles: corona analysis as a function of particle diameter and porosity. ACS Appl Mater Interfaces 2015, 7:21682-21689.

38. Elson EL. Fluorescence correlation spectroscopy: past, present, future. Biophys J 2011, 101:2855-2870.

39. Nienhaus GU, Maffre P, Nienhaus K. Studying the protein corona on nanoparticles by FCS. Methods Enzymol 2013, 519:115-137. 
40. Hong P, Koza S, Bouvier ES. Size-exclusion chromatography for the analysis of protein biotherapeutics and their aggregates. J Liq Chromatogr Relat Technol 2012, 35:2923-2950.

41. Mahmoudi M, Lynch I, Ejtehadi MR, Monopoli MP, Bombelli FB, Laurent S. Protein-nanoparticle interactions: opportunities and challenges. Chem Rev 2011, 111:5610-5637.

42. Teichroeb JH, Forrest JA, Jones LW. Size-dependent denaturing kinetics of bovine serum albumin adsorbed onto gold nanospheres. Eur. Phys. J. E 2008, 26:411-415.

43. Kaufman ED, Belyea J, Johnson MC, Nicholson ZM, Ricks JL, Shah PK, Bayless M, Pettersson T, Feldotö Z, Blomberg E. Probing protein adsorption onto mercaptoundecanoic acid stabilized gold nanoparticles and surfaces by quartz crystal microbalance and $\zeta$-potential measurements. Langmuir 2007, 23:6053-6062.

44. Lundqvist M, Sethson I, Jonsson B-H. Protein adsorption onto silica nanoparticles: conformational changes depend on the particles' curvature and the protein stability. Langmuir 2004, 20:10639-10647.

45. Norde W, Giacomelli CE. BSA structural changes during homomolecular exchange between the adsorbed and the dissolved states. I Biotechnol 2000, 79:259-268.

46. Shang L, Wang Y, Jiang J, Dong S. pH-dependent protein conformational changes in albumin: gold nanoparticle bioconjugates: a spectroscopic study. Langmuir 2007, 23:2714-2721.

47. Brandes N, Welzel PB, Werner C, Kroh LW. Adsorption-induced conformational changes of proteins onto ceramic particles: differential scanning calorimetry and FTIR analysis. J Colloid Interface Sci 2006, 299:56-69.

48. Lacerda SHDP, Park JJ, Meuse C, Pristinski D, Becker ML, Karim A, Douglas JF. Interaction of gold nanoparticles with common human blood proteins. ACS Nano 2010, 4:365-379.

49. Lück M, Pistel K-F, Li Y-X, Blunk T, Müller RH, Kissel T. Plasma protein adsorption on biodegradable microspheres consisting of poly(d, 1-lactide-co-glycolide), poly(l-lactide) or ABA triblock copolymers containing poly (oxyethylene): influence of production method and polymer composition. J Control Release 1998, 55:107-120.

50. Gessner A, Lieske A, Paulke BR, Müller RH. Influence of surface charge density on protein adsorption on polymeric nanoparticles: analysis by two-dimensional electrophoresis. Eur J Pharm Biopharm 2002, 54:165-170.

51. Docter D, Distler U, Storck W, Kuharev J, Wunsch D, Hahlbrock A, Knauer SK, Tenzer S, Stauber RH. Quantitative profiling of the protein coronas that form around nanoparticles. Nat Protoc 2014, 9:2030-2044.
52. Tenzer S, Docter D, Rosfa S, Wlodarski A, Jr K, Rekik A, Knauer SK, Bantz C, Nawroth T, Bier C. Nanoparticle size is a critical physicochemical determinant of the human blood plasma corona: a comprehensive quantitative proteomic analysis. ACS Nano 2011, 5:7155-7167.

53. Zhang H, Burnum KE, Luna ML, Petritis BO, Kim JS, Qian WJ, Moore RJ, Heredia-Langner A, WebbRobertson BJ, Thrall BD, et al. Quantitative proteomics analysis of adsorbed plasma proteins classifies nanoparticles with different surface properties and size. Proteomics 2011, 11:4569-4577.

54. Lundqvist $M$, Stigler $J$, Cedervall $T$, Berggård $T$, Flanagan MB, Lynch I, Elia G, Dawson K. The evolution of the protein corona around nanoparticles: a test study. ACS Nano 2011, 5:7503-7509.

55. Dobrovolskaia MA, Patri AK, Zheng J, Clogston JD, Ayub N, Aggarwal P, Neun BW, Hall JB, McNeil SE. Interaction of colloidal gold nanoparticles with human blood: effects on particle size and analysis of plasma protein binding profiles. Nanomedicine 2009, 5:106-117.

56. Pozzi D, Caracciolo G, Capriotti AL, Cavaliere C, La Barbera G, Anchordoquy TJ, Laganà A. Surface chemistry and serum type both determine the nanoparticleprotein corona. J Proteomics 2015, 119:209-217.

57. Sempf K, Arrey T, Gelperina S, Schorge T, Meyer B, Karas M, Kreuter J. Adsorption of plasma proteins on uncoated PLGA nanoparticles. Eur J Pharm Biopharm 2013, 85:53-60.

58. Wang G, Papasani MR, Cheguru P, Hrdlicka PJ, Hill RA. Gold-peptide nanoconjugate cellular uptake is modulated by serum proteins. Nanomedicine 2012, 8:822-832.

59. Yang JA, Johnson BJ, Wu S, Woods WS, George JM, Murphy CJ. Study of wild-type alpha-synuclein binding and orientation on gold nanoparticles. Langmuir 2013, 29:4603-4615.

60. Milani S, Baldelli Bombelli F, Pitek AS, Dawson KA, Rädler J. Reversible versus irreversible binding of transferrin to polystyrene nanoparticles: soft and hard corona. ACS Nano 2012, 6:2532-2541.

61. Winzen S, Schoettler S, Baier G, Rosenauer C, Mailaender V, Landfester K, Mohr K. Complementary analysis of the hard and soft protein corona: sample preparation critically effects corona composition. Nanoscale 2015, 7:2992-3001.

62. Natte K, Friedrich JF, Wohlrab S, Lutzki J, von Klitzing R, Osterle W, Orts-Gil G. Impact of polymer shell on the formation and time evolution of nanoparticle-protein corona. Colloids Surf B Biointerfaces 2013, 104:213-220.

63. Wangoo N, Suri CR, Shekhawat G. Interaction of gold nanoparticles with protein: A spectroscopic study to monitor protein conformational changes. Appl Phys Lett 2008, 92:133104. 
64. Mahmoudi M, Shokrgozar MA, Sardari S, Moghadam MK, Vali H, Laurent S, Stroeve P. Irreversible changes in protein conformation due to interaction with superparamagnetic iron oxide nanoparticles. Nanoscale 2011, 3:1127-1138.

65. Ma Z, Bai J, Wang Y, Jiang X. Impact of shape and pore size of mesoporous silica nanoparticles on serum protein adsorption and RBCs hemolysis. ACS Appl Mater Interfaces 2014, 6:2431-2438.

66. Turci F, Ghibaudi E, Colonna M, Boscolo B, Fenoglio I, Fubini B. An integrated approach to the study of the interaction between proteins and nanoparticles. Langmuir 2010, 26:8336-8346.

67. Gheshlaghi ZN, Riazi GH, Ahmadian S, Ghafari M, Mahinpour R. Toxicity and interaction of titanium dioxide nanoparticles with microtubule protein. Acta Biochim Biophys Sin 2008, 40:777-782.

68. Kim HR, Andrieux K, Delomenie C, Chacun H, Appel M, Desmaele D, Taran F, Georgin D, Couvreur P, Taverna M. Analysis of plasma protein adsorption onto PEGylated nanoparticles by complementary methods: 2-DE, CE and protein lab-on-chip system. Electrophoresis 2007, 28:2252-2261.

69. Tenzer S, Docter D, Kuharev J, Musyanovych A, Fetz V, Hecht R, Schlenk F, Fischer D, Kiouptsi K, Reinhardt C, et al. Rapid formation of plasma protein corona critically affects nanoparticle pathophysiology. Nat Nanotechnol 2013, 8:772-781.

70. Thode K, Lück M, Semmler W, Müller RH, Kresse M. Determination of plasma protein adsorption on magnetic iron oxides: sample preparation. Pharm Res 1997, 14:905-910.

71. Brun E, Sicard-Roselli C. Could nanoparticle corona characterizationhelp for biological consequence prediction? Cancer Nanotechnol 2014, 5:13.

72. Caracciolo G, Cardarelli F, Pozzi D, Salomone F, Maccari G, Bardi G, Capriotti AL, Cavaliere C, Papi M, Lagana A. Selective targeting capability acquired with a protein corona adsorbed on the surface of 1,2-dioleoyl-3-trimethylammonium propane/ DNA nanoparticles. ACS Appl Mater Interfaces 2013, 5:13171-13179.

73. Caracciolo G, Pozzi D, Capriotti AL, Cavaliere C, Piovesana S, La Barbera G, Amici A, Laganà A. The liposome-protein corona in mice and humans and its implications for in vivo delivery. $J$ Mater Chem $B$ 2014, 2:7419-7428.

74. O’Connell DJ, Bombelli FB, Pitek AS, Monopoli MP, Cahill DJ, Dawson KA. Characterization of the bionano interface and mapping extrinsic interactions of the corona of nanomaterials. Nanoscale 2015, 7:15268-15276.

75. Ritz S, Schottler S, Kotman N, Baier G, Musyanovych A, Kuharev J, Landfester K, Schild H, Jahn O, Tenzer S, et al. Protein corona of nanoparticles: distinct proteins regulate the cellular uptake. Biomacromolecules 2015, 16:1311-1321.

76. Verma A, Stellacci F. Effect of surface properties on nanoparticle-cell interactions. Small 2010, 6:12-21.

77. Worrall JW, Verma A, Yan H, Rotello VM. "Cleaning" of nanoparticle inhibitors via proteolysis of adsorbed proteins. Chem Commun 2006:2338-2340.

78. Distler U, Kuharev J, Navarro P, Levin Y, Schild H, Tenzer S. Drift time-specific collision energies enable deep-coverage data-independent acquisition proteomics. Nat Methods 2014, 11:167-170.

79. Schaffler M, Semmler-Behnke M, Sarioglu $H$, Takenaka S, Wenk A, Schleh C, Hauck SM, Johnston BD, Kreyling WG. Serum protein identification and quantification of the corona of 5, 15 and $80 \mathrm{~nm}$ gold nanoparticles. Nanotechnology 2013, 24:265103.

80. Dell'Orco D, Lundqvist M, Oslakovic C, Cedervall T, Linse S. Modeling the time evolution of the nanoparticle-protein corona in a body fluid. PLoS One 2010, 5:e10949.

81. Docter D, Westmeier D, Markiewicz M, Stolte S, Knauer SK, Stauber RH. The nanoparticle biomolecule corona: lessons learned - challenge accepted? Chem Soc Rev 2015, 44:6094-6121.

82. Pitek AS, O’Connell D, Mahon E, Monopoli MP, Baldelli Bombelli F, Dawson KA. Transferrin coated nanoparticles: study of the bionano interface in human plasma. PLoS One 2012, 7:e40685.

83. Barran-Berdon AL, Pozzi D, Caracciolo G, Capriotti AL, Caruso G, Cavaliere C, Riccioli A, Palchetti S, Lagana A. Time evolution of nanoparticleprotein corona in human plasma: relevance for targeted drug delivery. Langmuir 2013, 29:6485-6494.

84. Darabi Sahneh F, Scoglio C, Riviere J. Dynamics of nanoparticle-protein corona complex formation: analytical results from population balance equations. PLoS One 2013, 8:e64690.

85. Vilaseca P, Dawson KA, Franzese G. Understanding and modulating the competitive surface-adsorption of proteins through coarse-grained molecular dynamics simulations. Soft Matter 2013, 9:6978-6985.

86. Ding HM, Ma YQ. Computer simulation of the role of protein corona in cellular delivery of nanoparticles. Biomaterials 2014, 35:8703-8710.

87. Dobay MPD, Alberola AP, Mendoza ER, Rädler JO. Modeling nanoparticle uptake and intracellular distribution using stochastic process algebras. J Nanopart Res 2012, 14.

88. Klein J. Probing the interactions of proteins and nanoparticles. Proc Natl Acad Sci U S A 2007, 104: 2029-2030.

89. Polyak B, Cordovez B. How can we predict behavior of nanoparticles in vivo? Nanomedicine 2016, 11:189-192. 
90. Caracciolo G, Farokhzad OC, Mahmoudi M. Biological identity of nanoparticles in vivo: clinical implications of the protein corona. Trends Biotechnol 2016.

91. Lynch I, Dawson KA. Protein-nanoparticle interactions. Nano Today 2008, 3:40-47.

92. Pearson RM, Juettner VV, Hong S. Biomolecular corona on nanoparticles: a survey of recent literature and its implications in targeted drug delivery. Front Chem 2014, 2:108.

93. Saptarshi SR, Duschl A, Lopata AL. Interaction of nanoparticles with proteins: relation to bio- reactivity of the nanoparticle. J Nanobiotechnol 57 2013, 11:1.

94. Sanchez-Moreno P, Buzon P, Boulaiz H, Peula- 59 Garcia JM, Ortega-Vinuesa JL, Luque I, 60 Salvati A, Marchal JA. Balancing the effect of 61 corona on therapeutic efficacy and macrophage 62 uptake of lipid nanocapsules. Biomaterials 2015, 63 61:266-278.

95. Treuel L, Jiang X, Nienhaus GU. New views on cellular uptake and trafficking of manufactured nanoparticles. J R Soc Interface 2013, 10:20120939. 


\section{Graphical abstract}

Protein corona and nanoparticles: how can we investigate on?

Protein corona and nanoparticles: how can we investigate on? 60

Francesca Pederzoli ${ }^{1}$, Giovanni Tosi ${ }^{1}$, Maria Angela Vandelli ${ }^{1}$, Daniela Belletti ${ }^{1}$, Flavio Forni ${ }^{1}$, Barbara Ruozi ${ }^{1}$

METHODS FOR PROTEIN CORONA CHARACTERIZATION

SOFT CORONA

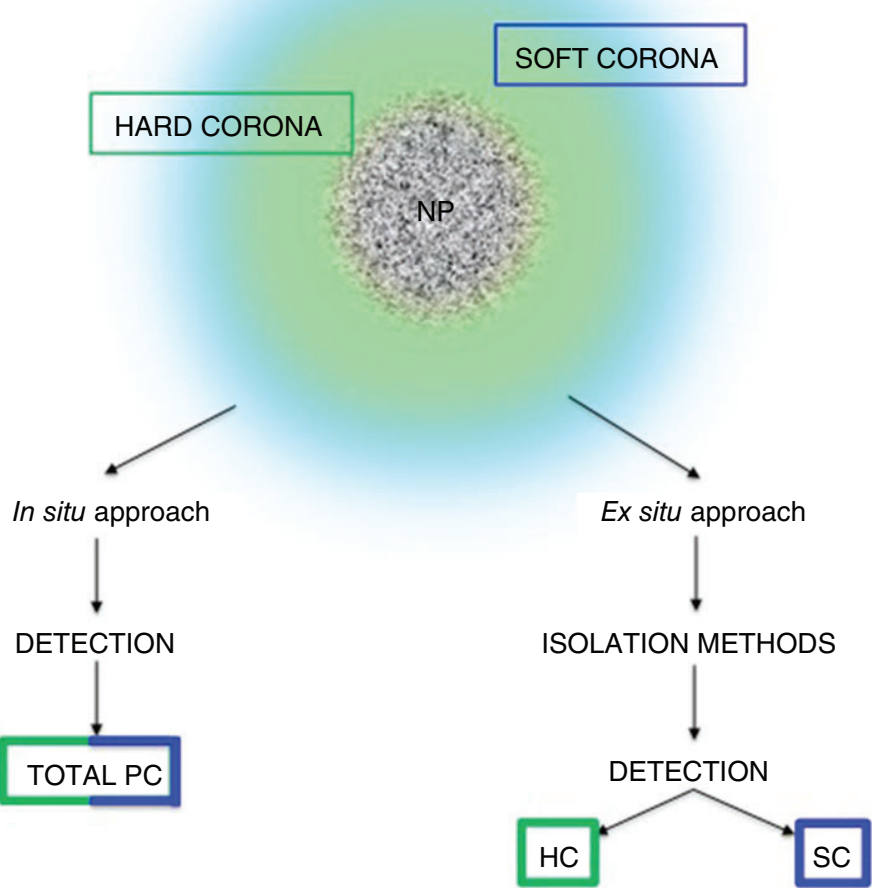


QUERIES TO BE ANSWERED BY AUTHOR

IMPORTANT NOTE: Please mark your corrections and answers to these queries directly onto the proof at the relevant place. DO NOT mark your corrections on this query sheet.

\section{Queries from the Copyeditor:}

AQ1. Please confirm that given names (red) and surnames/family names (green) have been identified correctly.

AQ2. A running head short title was not supplied; please check if this one is suitable and, if not, please supply a short title that can be used instead.

AQ3. As per style, graphical abstract text is mandatory. Please provide the same.

AQ4. The year of publication in reference Sakulkhu et al. (2013) [14] does not match with the reference list. Please check and amend if necessary.

AQ5. The year of publication in reference Ashby et al. (2013) [18] does not match with the reference list. Please check and amend if necessary.

AQ6. References have been renumbered. Please check and confirm.

AQ7. Please provide publisher name and location in Ref. [13].

AQ8. Please provide Volume number for Ref. [77].

AQ9. Please provide Page range for ref. [87].

AQ10. Please provide Volume number, Page range for ref. [90]. 
Required software to e-Annotate PDFs: Adobe Acrobat Professional or Adobe Reader (version $\mathbf{7 . 0}$ or above). (Note that this document uses screenshots from Adobe Reader $\mathbf{X}$ )

The latest version of Acrobat Reader can be downloaded for free at: http://get.adobe.com/uk/readerl

Once you have Acrobat Reader open on your computer, click on the Comment tab at the right of the toolbar:

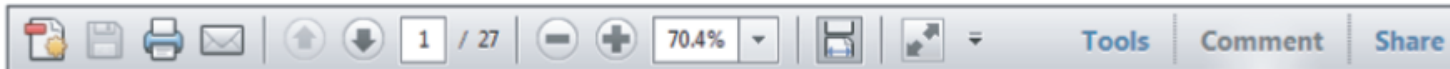

This will open up a panel down the right side of the document. The majority of tools you will use for annotating your proof will be in the Annotations section, pictured opposite. We've picked out some of these tools below:

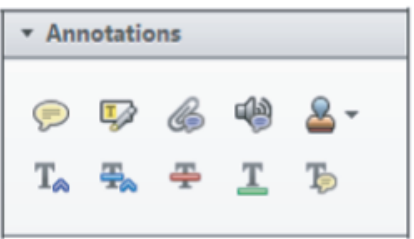

1. Replace (Ins) Tool - for replacing text.

军 Strikes a line through text and opens up a text box where replacement text can be entered.

\section{How to use it}

- Highlight a word or sentence.

- Click on the Replace (Ins) icon in the Annotations section.

- Type the replacement text into the blue box that appears.

1dard tramework for the analysis of $\mathrm{m}$ icy Nevertheless, it alse-led to exog،

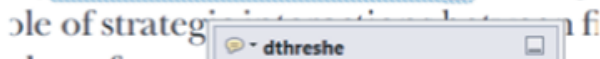
aber of comp 08/06/2011 15:58:17 : is that the $\mathrm{si}$, which led of nain compo bo level, are exc nc

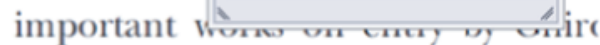
M heneferth) 1 we snen the 'hlarl 1

3. Add note to text Tool - for highlighting a section to be changed to bold or italic.

T. Highlights text in yellow and opens up a text box where comments can be entered.

\section{How to use it}

- Highlight the relevant section of text.

- Click on the Add note to text icon in the Annotations section.

- Type instruction on what should be changed regarding the text into the yellow box that appears.

namic responses of mark ups ent with the VAR evidence

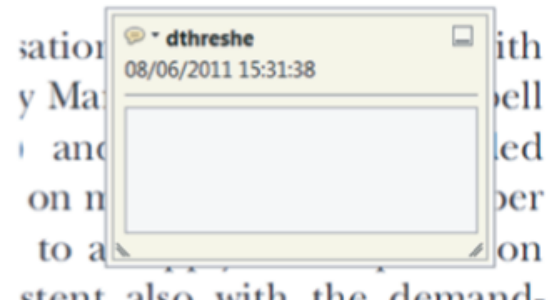

2. Strikethrough (Del) Tool - for deleting text.

Strikes a red line through text that is to be deleted.

\section{How to use it}

- Highlight a word or sentence.

- Click on the Strikethrough (Del) icon in the Annotations section.

there is no room for extra prohts al : ups are zero and the number of set) values are not determined by Blanchard and Kivetaki (1987), sfect competition in general equilil ts of aggregate demand and supply lassical framework assuming monol een on evorensue number of firms

4. Add sticky note Tool - for making notes at specific points in the text.

Marks a point in the proof where a comment needs to be highlighted.

How to use it

- Click on the Add sticky note icon in the Annotations section.

- Click at the point in the proof where the comment should be inserted.

- Type the comment into the yellow box that appears.

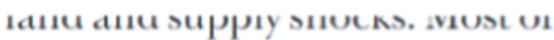

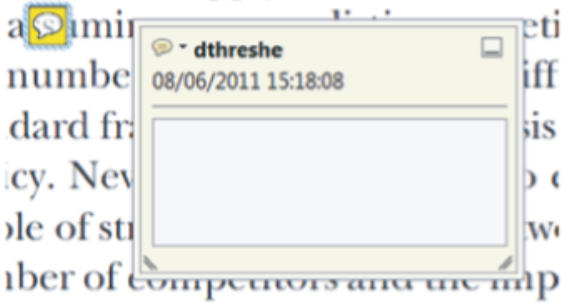

is that the structure of the sects: 
5. Attach File Tool - for inserting large amounts of text or replacement figures.

Inserts an icon linking to the attached file in the appropriate pace in the text.

\section{How to use it}

- Click on the Attach File icon in the Annotations section.

- Click on the proof to where you'd like the attached file to be linked.

- Select the file to be attached from your computer or network.

- Select the colour and type of icon that will appear in the proof. Click OK.

\section{E N D}

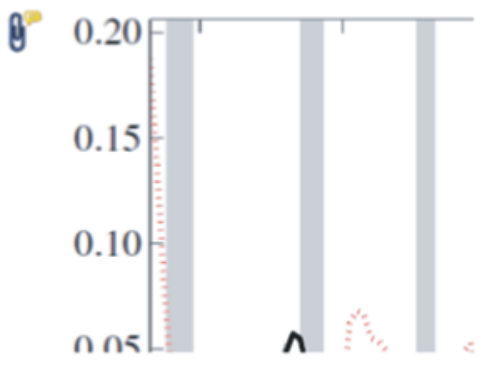

6. Add stamp Tool - for approving a proof if no corrections are required.

- Inserts a selected stamp onto an appropriate place in the proof.

\section{How to use it}

- Click on the Add stamp icon in the Annotations section.

- Select the stamp you want to use. (The Approved stamp is usually available directly in the menu that appears).

- Click on the proof where you'd like the stamp to appear. (Where a proof is to be approved as it is, this would normally be on the first page).

tr the Dusiness cycie, starung with the on perfect competition, constant ret hy otaki (1987), has introduced produc general equilibrium models with nomin:

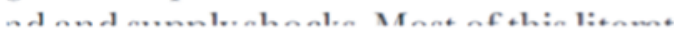

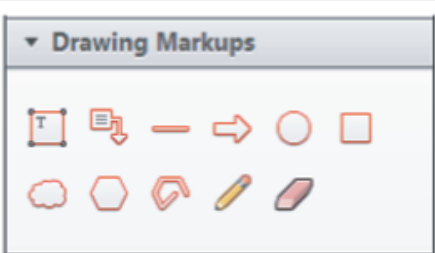

\section{How to use it}

- Click on one of the shapes in the Drawing Markups section.

- Click on the proof at the relevant point and draw the selected shape with the cursor.

- To add a comment to the drawn shape, move the cursor over the shape until an arrowhead appears.

- Double click on the shape and type any text in the red box that appears.
7. Drawing Markups Tools - for drawing shapes, lines and freeform annotations on proofs and commenting on these marks.

Allows shapes, lines and freeform annotations to be drawn on proofs and for comment to be made on these marks..

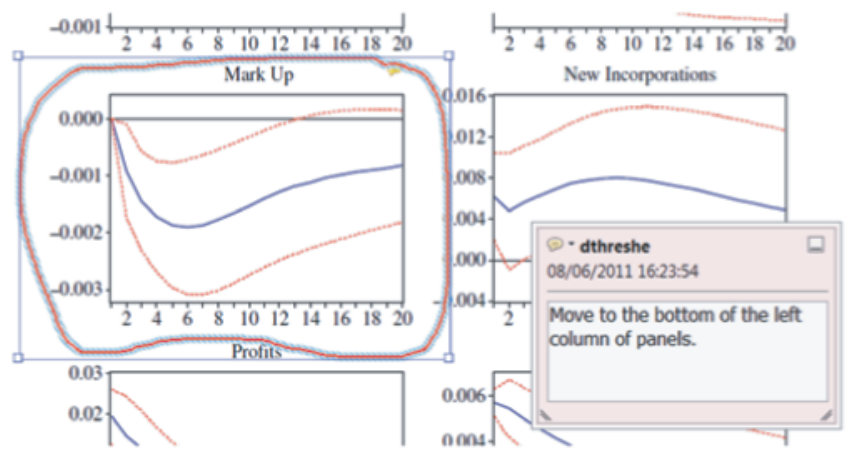

For further information on how to annotate proofs, click on the Help menu to reveal a list of further options:

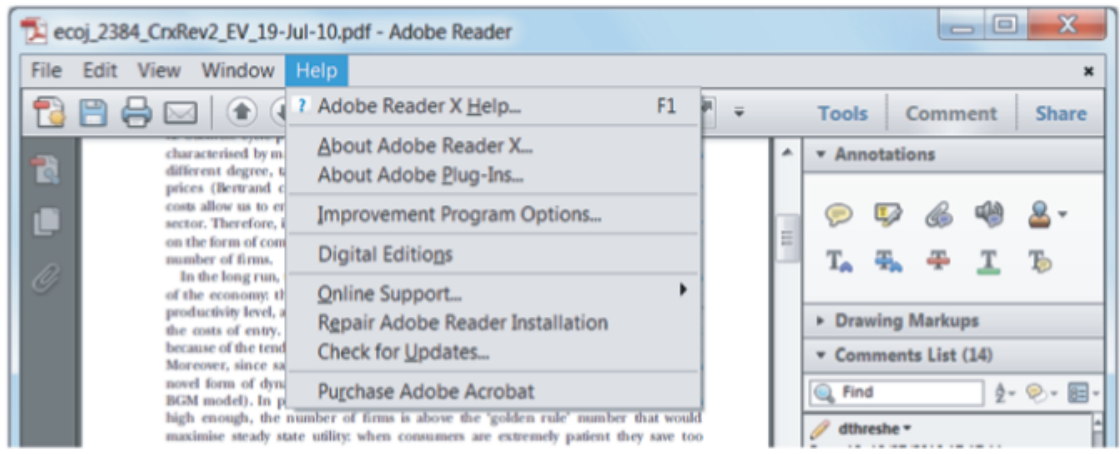

